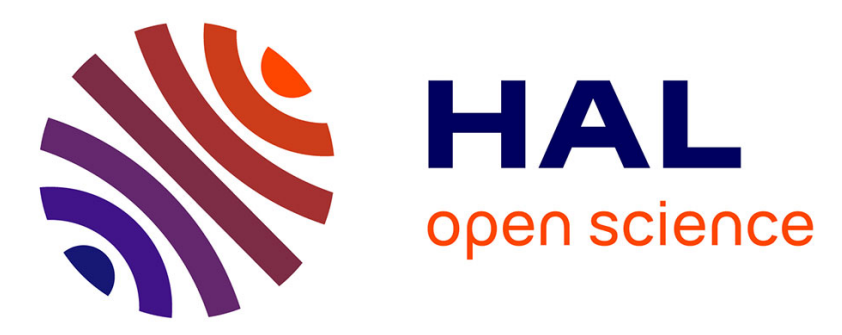

\title{
Influence of polycarboxylate superplasticizer, citric acid and their combination on the hydration and workability of calcium sulfoaluminate cement
}

Rachid Belhadi, Alexandre Govin, Philippe Grosseau

\section{- To cite this version:}

Rachid Belhadi, Alexandre Govin, Philippe Grosseau. Influence of polycarboxylate superplasticizer, citric acid and their combination on the hydration and workability of calcium sulfoaluminate cement. Cement and Concrete Research, 2021, 147, pp.106513. 10.1016/j.cemconres.2021.106513 . emse03267038

HAL Id: emse-03267038

https://hal-emse.ccsd.cnrs.fr/emse-03267038

Submitted on 24 Jun 2021

HAL is a multi-disciplinary open access archive for the deposit and dissemination of scientific research documents, whether they are published or not. The documents may come from teaching and research institutions in France or abroad, or from public or private research centers.
L'archive ouverte pluridisciplinaire HAL, est destinée au dépôt et à la diffusion de documents scientifiques de niveau recherche, publiés ou non, émanant des établissements d'enseignement et de recherche français ou étrangers, des laboratoires publics ou privés. 


\section{Influence of polycarboxylate superplasticizer, citric acid and} their combination on the hydration and workability of calcium sulfoaluminate cement

Rachid BELHADI, Alexandre GOVIN*, Philippe GROSSEAU

Mines Saint-Etienne, Univ Lyon, CNRS, UMR 5307 LGF, Centre SPIN, F - 42023 SaintEtienne France

*Corresponding author: $\quad$ Tel: +33477420253

E-mail address: govin@emse.fr 


\begin{abstract}
PCEs are well known to improve the initial fluidity of CSA. However, their dispersion efficiency drops quickly over time. This issue can be solved by incorporating retarders. In this context, this paper deals with the influence of citric acid, used as a retarder, PCE and their combination on the hydration and workability of CSA. Isothermal calorimetry, XRD and TG analysis were used to describe the hydration process, while workability was characterized with the mini-cone test. Adsorption behavior was investigated using total organic carbon analyzer coupled with ion chromatography. Results show that the introduction of citric acid retained the dispersion efficiency of PCE over time. However, the initial dispersion efficiency of PCE was decreased by citric acid as the latter tend to adsorb first on the surface of cement grains, inhibiting the adsorption of PCE. A dispersion model was proposed to describe the acting mechanism of these admixtures on CSA.
\end{abstract}

Keywords: Polycarboxylate superplasticizer, Sulfoaluminate cement, Retarder, Hydration, Workability. 


\section{Introduction}

Cement industry is the second-largest industrial $\mathrm{CO}_{2}$ emitter globally, and the third-largest industrial energy consumer with a consumption of $7 \%$ of the industrial energy use [1]. Ordinary Portland cement (OPC) is the most used type of cement thanks to its reliability, durability, low economic cost and thanks to its relatively low energy consumption and $\mathrm{CO}_{2}$ emissions compared to other construction materials such as iron, aluminum and wood [2-4]. However, in sum the production of OPC accounts for 5-8\% of the total man-made $\mathrm{CO}_{2}$ emissions, as the production of 1 ton of $\mathrm{OPC}$ releases $\approx 0.87$ ton of $\mathrm{CO}_{2}[5,6]$. In this context, cement industry is highly requested to reduce energy consumption and greenhouse gases emissions. Several strategies were identified in order to reduce the environmental impact of cement industry such as: (i) the use of alternative fuels and raw materials in the production process of OPC [7,8]; (ii) the use of supplementary cementing materials, such as fly ash, silica fume, calcined clay, pozollan and ground granulated blast furnace slag [9,10]; (iii) the development of new low- $\mathrm{CO}_{2}$ binders, such as alkali-activated materials, geopolymers, calcium aluminate cement, limestone calcined clay cement and calcium sulfoaluminate cement $[3,11-13]$; (iv) the carbon capture and storage $[14,15]$.

Besides its harmful effect on environment, OPC cannot be used in certain applications where a rapid gain in resistance is required. Therefore, the use of alternative binders is of high interest.

Calcium sulfoaluminate cements (CSA), known as "the third cement series" in China, are attracting increasing attention in research and practice as they promise to provide an energyefficient and low- $\mathrm{CO}_{2}$ alternative to OPC [4]. CSA contains less amount of limestone to be decarbonated compared to OPC and the maximum kiln temperature for CSA clinker production is typically $1250{ }^{\circ} \mathrm{C}$, around $200{ }^{\circ} \mathrm{C}$ less than for OPC clinker production. Additionally, CSA clinkers require less energy for grinding as they tend to be more friable 
than OPC clinkers $[4,16]$. Typically, CSA consists of ye'elimite $\left(\mathrm{C}_{4} \mathrm{~A}_{3} \$\right)$ as a major phase (45-75\%), calcium sulfate (including gypsum $\mathrm{C} \$ \mathrm{H}_{2}$ and/or anhydrite $\mathrm{C} \$$ ), belite $\left(\mathrm{C}_{2} \mathrm{~S}\right)$, bredigite $\left(\mathrm{Ca} 7 \mathrm{Mg}\left(\mathrm{SiO}_{4}\right)_{4}\right)$, and other minor phases such as calcium aluminate $\left(\mathrm{C}_{3} \mathrm{~A}, \mathrm{CA}\right.$, $\left.\mathrm{C}_{12} \mathrm{~A}_{7}, \mathrm{CA}_{2}\right)$ and brownmillerite $\left(\mathrm{C}_{4} \mathrm{AF}\right)[3,17,18]$. The hydration kinetics of CSA are mainly controlled by the type and the amount of calcium sulfate they contain $[19,20]$. When sufficient amount of calcium sulfate is available in the phase composition, ye'elimite reacts quickly to form crystalline ettringite $\left(\mathrm{C}_{6} \mathrm{~A} \$_{3} \mathrm{H}_{32}\right)$ and amorphous aluminum hydroxide $\left(\mathrm{AH}_{3}\right)$ according to Eq. (1) and/or Eq. (2) [3,21,22]. For a calcium sulfate to ye'elimite molar ratio lower than 2, monosulfate $\left(\mathrm{C}_{4} \mathrm{~A} \$ \mathrm{H}_{12}\right)$ will be formed according to Eq. (3) [3].

$$
\begin{aligned}
& C_{4} A_{3} \$+2 C \$+38 H \rightarrow C_{6} A \$_{3} H_{32}+2 A H_{3} \\
& C_{4} A_{3} \$+2 C \$ H_{2}+34 H \rightarrow C_{6} A \$_{3} H_{32}+2 A H_{3} \\
& C_{4} A_{3} \$+18 H \rightarrow C_{4} A \$ H_{12}+2 A H_{3}
\end{aligned}
$$

Due to their rapid-hardening, poor workability [23-25] and their low $\mathrm{pH}$ as compared to OPC, CSAs have been widely used in small-scale repairs [26], permeability resistance engineering $[27,28]$ and waste encapsulation [29-31]. In order to extend their use to larger-scale applications, addition of superplasticizers and retarders were suggested by several authors [24,26,32]. Polycarboxylate superplasticizers (PCE) are the newest and the most widely used superplasticizers in concrete. They adsorb on the surface of particles, inducing their dispersion through steric hindrance [33-35]. Usually, PCEs are added with a dosage ranging between $0.12 \mathrm{wt} \%$ and $0.2 \mathrm{wt} \%$ [36].

PCEs are known to well improve the initial fluidity of CSA pastes, but lose their dispersion efficiency rapidly due to the high reactivity of CSA [24]. Retarders, such as borax [36-39], sodium gluconate [37,40], tartaric acid [37] and citric acid [26,38,40], may be used in order to overcome the quick loss of dispersion efficiency of PCEs. In cement paste, these retarders tend to form a highly negatively charged complexes with $\mathrm{Ca}^{2+}[36,37,41,42]$, and adsorb on 
the surface of minerals leading to a decrease in the consumption of free water and PCEs by the hydrates [36]. Consequently, the dispersion efficiency of PCEs can be maintained over time. Zhang et al. [40] investigated the combined effect of PCEs and two retarders (citric acid and sodium gluconate) on the fluidity and strength of CSA. The results showed an increase of the initial fluidity of CSA pastes and a retained workability over time. Tan et al. [36] highlighted an enhancement of the PCE's dispersion efficiency by borax, when the dosage of the latter was less than $0.4 \%$ by mass of cement. However, the combination of several admixtures in cement paste may cause undesired interactions. Indeed, competitive adsorption between these admixtures on the surface sites of cement particles may occur, which may influence their performances [43-45]. When combining PCE with sodium gluconate (NG) or with hydroxyethyl cellulose (HEC), Bessaies-Bey et al. [44] found that NG is able to fully desorb the pre-adsorbed PCE while PCE was also able to fully desorb the pre-adsorbed HEC. As a result of this competitive adsorption between these admixtures, the yield stress and viscosity of the paste were decreased. In addition, Govin et al. [45] highlighted a decrease of the dispersing effectiveness of PCE when combined with hydroxypropyl guar (HPG). The authors demonstrated that the admixtures (PCE and HPG), which were introduced at the same time, competed for adsorption, which explains the decrease of the yield stress of the paste. Furthermore, Plank and Winter [46] investigated the competitive adsorption between PCEs and retarders in cementitious self-levelling underlayments based on OPC, CAC and anhydrite. They found that citric acid forms highly charged complexes with $\mathrm{Ca}^{2+}$ and hinder the adsorption of PCE, which resulted in a decrease in the paste workability. Moreover, Tan et al. [36] highlighted a decrease of the PCE's dispersing efficiency in CSA pastes when the dosage of borax was more than $0.4 \%$ by mass of cement.

Considering citric acid as one of the primary set retarding agents recommended for CSA, little research has investigated the combined effect of PCE with citric acid on the hydration and the 
workability of CSA pastes. Therefore, this study was conducted in order to understand the effect of citric acid on the dispersion efficiency of PCE in CSA systems.

\section{Experimental program}

\subsection{Materials}

A commercial CSA (i.tech ALICEM), provided by Italcementi Group, was investigated. The chemical composition of the cement was obtained by X-Ray fluorescence (XRF), while phase composition was determined by X-Ray diffraction and quantified by mean of Rietveld refinement [47] using Topas software [48]. 40\% of $\mathrm{ZnO}$ was used as an internal standard for amorphous phase's quantification. As shown in Table 1, CSA was mainly composed of ye'elimite ( $49 \mathrm{wt} \%)$, anhydrite $(\sim 22 \mathrm{wt} \%)$ and bredigite $(\sim 11 \mathrm{wt} \%)$. The latter is a calcium magnesium silicate phase, characterized by a poor reactivity $[17,49]$. Besides other minor crystalline phases $\left(\mathrm{CaF}_{2} ; \mathrm{C}_{12} \mathrm{~A}_{7} ; \mathrm{MgO}\right), 14 \%$ of amorphous phases $(\mathrm{Am})$ were quantified. Similar amount, 10 - $25 \mathrm{wt} \%$, of these latter phases were found in CSA cements by ÁlvarezPinazo et al. [50].

Table 1. Chemical and phase composition of CSA used.

\begin{tabular}{|c|c|c|c|c|c|c|c|c|c|c|}
\hline \multirow{2}{*}{ Chemical composition (\%) } & $\mathrm{Al}_{2} \mathrm{O}_{3}$ & $\mathrm{CaO}$ & $\mathrm{SO}_{3}$ & $\mathrm{SiO}_{2}$ & $\mathrm{CO}_{2}$ & $\mathrm{Fe}_{2} \mathrm{O}_{3}$ & $\mathrm{MgO}$ & $\mathrm{Na}_{2} \mathrm{O}$ & $\mathrm{K}_{2} \mathrm{O}$ & $\mathrm{TiO}_{2}$ \\
\hline & 20.2 & 38.9 & 22.9 & 6.7 & 3.4 & 1.1 & 2.0 & 0.9 & 0.5 & 0.3 \\
\hline \multirow{2}{*}{ Phase composition (\%) } & \multicolumn{2}{|c|}{$\mathrm{C}_{4} \mathrm{~A}_{3} \$$} & \multicolumn{2}{|c|}{$\mathrm{C} \$$} & \multicolumn{2}{|c|}{$\mathrm{Ca} 7 \mathrm{Mg}\left(\mathrm{SiO}_{4}\right)_{4}$} & \multicolumn{2}{|c|}{$\mathrm{C}_{12} \mathrm{~A}_{7}$} & $\mathrm{CaF}_{2}$ & $\mathrm{Am}$ \\
\hline & \multicolumn{2}{|c|}{48.8} & \multicolumn{2}{|c|}{22.2} & \multicolumn{2}{|c|}{11.0} & \multicolumn{2}{|c|}{1.1} & 0.8 & 14.0 \\
\hline
\end{tabular}

A/NQC: Amorphous and/or non-quantified crystalline phases

A polycarboxylate superplasticizer (PCE), composed of a polymethacrylic acid backbone and grafted side chains of polyethylene oxide (Fig. 1,a), was used. The main characteristics of the PCE, given by the manufacturer (CHRYSO), are listed in Table 2. The charge density of the PCE was measured experimentally by conductimetric titration with $\mathrm{NaOH}$. Additionally, a 
commercial citric acid (99.5\% Honeywell) was used as a retarder. Its chemical structure is shown in Fig. 1, b. In the rest of this paper, citric acid will be noted AC.

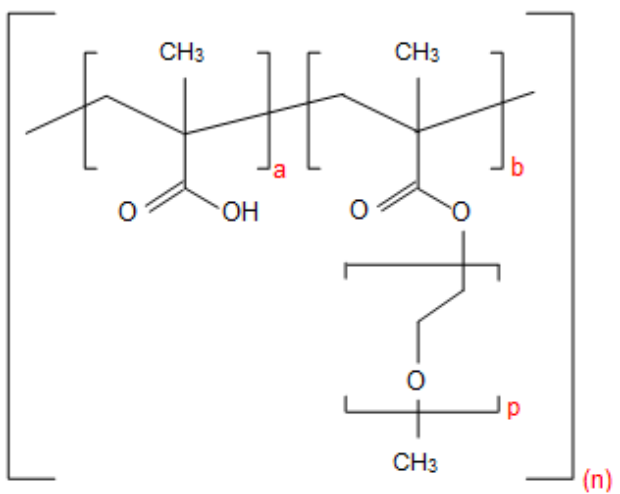

(a)

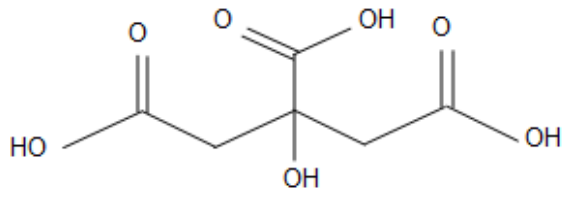

(b)

Fig. 1 (a) Structure of the PCE used. The PCE contains n segments, each with one side chain.

Each side chain contains p monomers. Each segment contains $\mathrm{N}=\mathrm{a}+\mathrm{b}$ monomers ; (b)

Chemical structure of AC.

Table 2. Characteristics of the PCE used

\begin{tabular}{cccccccc}
\hline & $\begin{array}{c}\text { Solid content } \\
(\%)\end{array}$ & $\begin{array}{c}\text { Mw } \\
(\mathrm{g} / \mathrm{mol})\end{array}$ & $\begin{array}{c}\text { Charge density } \\
(\mathrm{mmol} / \mathrm{g})\end{array}$ & $\mathrm{P}$ & $\mathrm{N}=\mathrm{a}+\mathrm{b}$ & $\mathrm{n}$ & $\begin{array}{c}\text { Backbone } \\
\text { conformation }\end{array}$ \\
\cline { 2 - 7 } PCE & 48300 & 0.79 & 45 & 5 & 12 & FBW \\
\hline
\end{tabular}

FBW : Flexible Backbone Warm, according to Gay and Raphael [51]

\subsection{Paste preparation}

Cement pastes were prepared with deionized water at a fixed water-to-cement ratio (W/C) of

0.4. This value of $\mathrm{W} / \mathrm{C}$ ratio is often used in practice for $\mathrm{CSA}$ concrete $(0.3 \leq \mathrm{W} / \mathrm{C} \leq 0.45)$

[52]. The admixtures (PCE and AC) were added into the dry mix at the same time as the water with a dosage of $0.2 \%$ by mass of cement. As the PCE was in suspension, the amount of water 
contained in the PCE's solution was taken into account in order to maintain a constant W/C ratio between all the formulations.

All the pastes were mixed according to the standard NF EN 196-1 [53] except pastes prepared for calorimetry measurements. At chosen times $(30 \mathrm{~min}, 1 \mathrm{~h} 30 \mathrm{~min}, 2 \mathrm{~h} 30 \mathrm{~min}, 4 \mathrm{~h}, 6 \mathrm{~h}, 8 \mathrm{~h}$, $24 \mathrm{~h}$ and $48 \mathrm{~h}$ ), the hydration was stopped using the solvent exchange method [54]. It consisted in immersing the crushed pastes into $50 \mathrm{ml}$ of isopropanol for $15 \mathrm{~min}$. Then the suspension was vacuum filtered. The retentate was rinsed once with isopropanol and twice with diethyl ether. Finally, the residue was dried in an oven at $40 \pm 2{ }^{\circ} \mathrm{C}$ and manually grounded to a particle size less than $100 \mu \mathrm{m}$. The solid was then put into closed bottles and stored in a desiccator over silica gel until analysis by thermogravimetry (TGA) and X-ray diffraction $(\mathrm{XRD})$

\subsection{Methods}

The heat evolution during cement hydration was measured with an isothermal heat flow calorimeter (Calvet calorimeter C 80, SETARAM) at a constant temperature of $25 \pm 0.5^{\circ} \mathrm{C}$. The pastes were prepared by pre-mixing cement, admixtures and water for $30 \mathrm{~s}$ manually, then a small stirrer carried out the mixing for $1 \mathrm{~min}$ at $500 \mathrm{rpm}$. Paste samples of $1.5 \mathrm{~g}$ approximately were placed into the calorimeter and the heat flow was recorded for $48 \mathrm{~h}$.

TG measurements were carried out on a TG 92 SETARAM. After the stoppage of hydration, the weight loss as a function of temperature was determined on $150 \mathrm{mg}$ of powder samples. The temperature range was $30-900^{\circ} \mathrm{C}$ with a heating rate of $10^{\circ} \mathrm{C} / \mathrm{min}$ under $\mathrm{He}$ atmosphere. The Fityk software was used to fit DTG curves and to integrate the peak area using a Pearson 7 function. The amount of hydrates was calculated as follow:

$$
p_{i}=\frac{A_{i} \times M_{i}}{n_{E i} \times M_{H_{2} O}}
$$


Where $\mathrm{p}_{\mathrm{i}}$ is the amount of the phase $\mathrm{i} ; \mathrm{A}_{\mathrm{i}}$ is the integrated area of the peak corresponding to the phase $\mathrm{i} ; \mathrm{n}_{\mathrm{Ei}}$ represents the number of water molecules bound by the phase $\mathrm{i}$ (ettringite was considered to bound only 30 molecules of water [55]); $M_{\mathrm{H}_{2} \mathrm{O}}$ and $\mathrm{M}_{\mathrm{i}}$ are the molar masses of water and the phase i respectively.

Knowing that the weight of the solid fraction of the sample is changing during hydration, the results were rescaled to a common basis as follow [56]:

Per $100 \mathrm{~g}$ anhydrous:

$$
p_{i r}=\frac{p_{i}}{1-H_{2} O_{B}}
$$

Where $\mathrm{p}_{\mathrm{ir}}$ is the amount of the phase $\mathrm{i}$ rescaled to $100 \mathrm{~g}$ of anhydrous, $\mathrm{p}_{\mathrm{i}}$ is the amount of the measured phase $\mathrm{i}$ determined above, $\mathrm{H}_{2} \mathrm{O}_{\mathrm{B}}$ is the bound water content, which corresponds to the weight loss of the sample heated at $600{ }^{\circ} \mathrm{C}$.

XRD analyses were performed on a Bruker diffractometer (D8_A25 with a LYNXEYE XET detector and $\mathrm{CuK} \alpha$ radiation). The measurements were made over an angular range of $5^{\circ}-90^{\circ}$ $2 \theta$ with a step size of $0.015^{\circ}$. To minimize preferred orientation, back loading and sample rotation were adopted [56]. The phase identification was realized using the DiffracEVA software and the ICDD database [57]. The phase composition was determined using the Rietveld refinement. $40 \mathrm{wt} \%$ of zinc oxide ( $\mathrm{ZnO}$, MERCK), was added as an internal standard for Am phase quantification. The estimated amount of Am phase was determined as follow:

$$
\% A m=\frac{\% Z n O_{\text {Rietveld }}-\% Z n O_{\text {Introduced }}}{\% Z n O_{\text {Rietveld }}} \times 100
$$

where $\% \mathrm{Am}$ is the amount of amorphous phases and $\% \mathrm{ZnO}_{\text {Rietveld }}$ is the amount of $\mathrm{ZnO}$ obtained by Rietveld refinement.

Crystalline phase's amount was then recalculated as follow: 


$$
\% \operatorname{Crp}=\frac{\% \operatorname{Crp}_{\text {Rietveld }}}{100} \times(100-\% A m)
$$

Where $\% \mathrm{Crp}$ is the amount of the crystalline phase, $\% \operatorname{Crp}_{\text {Rietveld }}$ is the amount of the crystalline phase determined by Rietveld refinement, and \% Am is determined above.

Finally, results were rescaled and normalized to $100 \mathrm{~g}$ of anhydrous as shown in Eq. (5).

Paste flow investigations were carried out through a mini-slump-cone (40 $\mathrm{mm}$ in height, 66 $\mathrm{mm}$ in top diameter, and $74.3 \mathrm{~mm}$ in bottom diameter). The cement paste was poured into the cone, and the cone was vertically removed. The spread flow of the paste was considered to be the mean diameter of the spread paste. The measurements were realized each $10 \mathrm{~min}$, from 8 min until there was no spread. The pastes were mechanically mixed for $30 \mathrm{~s}$, at $140 \mathrm{rpm}$, before each measurement.

The adsorption of admixtures (PCE and AC) on cement was measured using the depletion method. The quantification was made on the non-adsorbed admixture remaining in the interstitial solution. The interstitial solution was extracted by double centrifugation of the cement paste at $8 \mathrm{~min}, 18 \mathrm{~min}$ and $38 \mathrm{~min}$ after the start of mixing in case of the use of PCE alone. When PCE was combined with AC, the fluidity of the paste was retained over time, allowing extraction of the interstitial solution at longer times ( $8 \mathrm{~min}, 18 \mathrm{~min}, 38 \mathrm{~min}, 78 \mathrm{~min}$ and $118 \mathrm{~min})$. The first centrifugal separation was carried out at $5000 \mathrm{rpm}$ for $10 \mathrm{~min}$ using the Multifuge 3SR+ centrifuge (Thermofischer) and the second one was set out at $14500 \mathrm{rpm}$ using the miniSpin plus centrifuge (Eppendorf) for $5 \mathrm{~min}$.

When PCE and AC were introduced alone, the non-adsorbed admixture remaining within the interstitial solution was quantified by means of Total Organic Carbon (TOC). The TOC measurements were carried out using a Vario-TOC Cube (Elementar) at a temperature of 850 ${ }^{\circ} \mathrm{C}$. Once extracted, the supernatant was diluted 10 times with hydrochloric acid solution at 0.1 mol. $\mathrm{L}^{-1}$ in order to avoid carbonation of the samples. The adsorbed amount of admixture 
was calculated from reference measurements of aqueous admixture solutions. The initial organic carbon in pure cement was taken into account and deduced from the measurements.

When combining AC with PCE, TOC cannot differentiate between PCE and AC. To overcome this issue, the non-adsorbed $\mathrm{AC}$ remaining in the interstitial solution was quantified by mean of ion chromatography (IC) (DIONEX ICS 5000+, column CS12A, conductimetric detector). A gradient of $\mathrm{KOH}$ concentration was used as eluent. The samples were prepared by diluting the supernatant 100 times using a hydrochloric acid solution at 0.01 mol.L ${ }^{-1}$. The PCE concentration was calculated by subtracting the AC concentration measured by IC, from the TOC concentration. This method was used by Plank and Winter [46] and validated by using solutions with known concentrations of AC and PCE. An error of $\pm 2.5 \%$ was determined.

\section{Results and discussion}

\subsection{Hydration kinetics}

The hydration kinetics of CSA with and without admixtures, were investigated by mean of isothermal calorimetry. Without admixtures, the heat flow released by the hydration process of CSA, shown in Fig. 2, a began with an instantaneous increase in released heat due to the rapid initial dissolution of anhydrous CSA's phases $[25,58,59]$. The heat released during this initial period can be misinterpreted because of the external mixing adopted here and the sensitivity of the calorimeter [24,39], thus it was not considered in this paper. The first peak was followed by a short induction period that ends after only 45 min of hydration, showing the high reactivity of our CSA. Afterwards, the main hydration period started with a rapid release of a large quantity of heat, resulting in a main hydration peak at $85 \mathrm{~min}$. The increase of heat release may be attributed to the rapid dissolution of ye'elimite and anhydrite, and the strong precipitation of hydration products (presumably ettringite) as stated by several authors 
[24,59]. Finally, the heat flow started to decrease and reached a low-heat-release steady state condition. The decrease of the heat flow may have resulted from space and diffusion limitations due to the impingement of hydrates, decrease in the dissolution rate of anhydrous phases due to interactions between ions in the solution, and/or depletion of anhydrous phases.

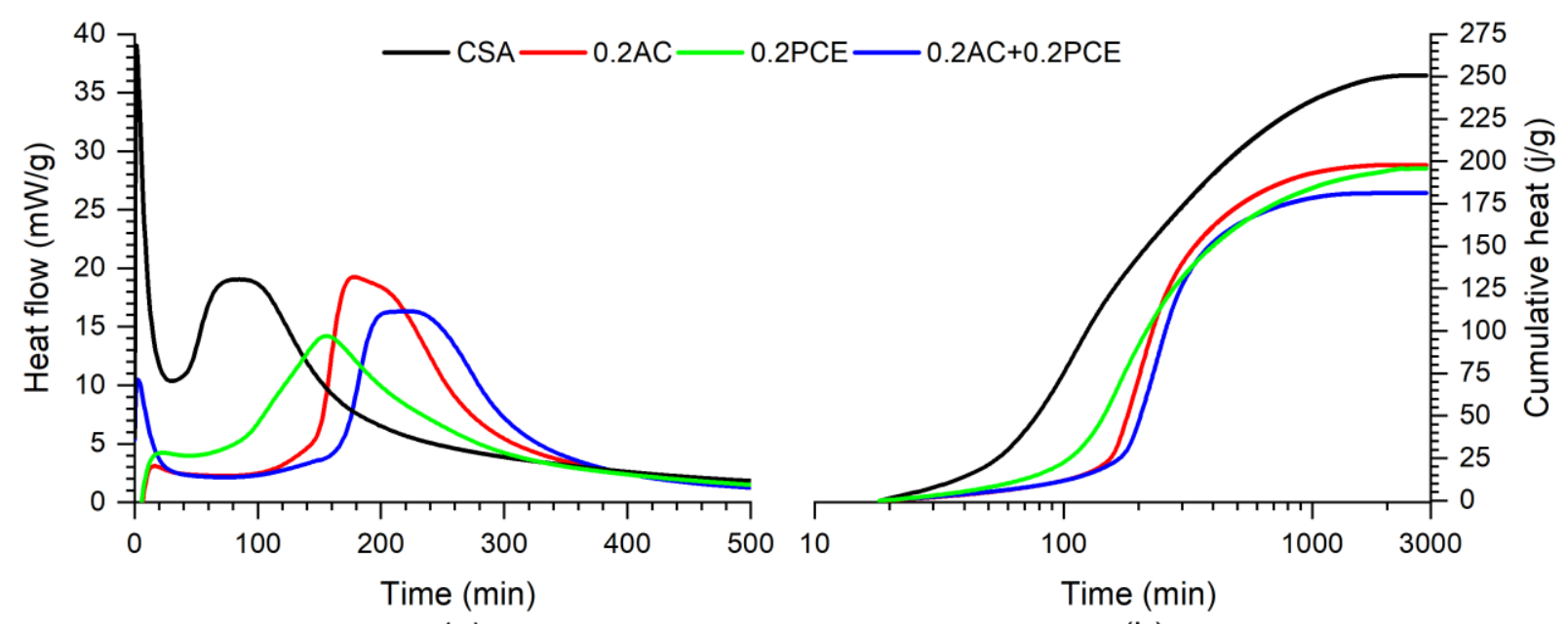

(a)

(b)

Fig. 2 (a) heat evolution of CSA with and without admixtures (AC and/or PCE) ; (b) cumulative released heat of CSA, influenced by admixtures. The dosage of admixtures was fixed at $0.2 \mathrm{wt} \%$

At a dosage of $0.2 \mathrm{wt} \%$, AC delayed the hydration of CSA by extending the induction period by almost 3.5 times compared to the reference sample. The retardation is likely due to the chelation of calcium ions by the citrate $[32,60]$, preventing the precipitation of hydrates (discussed later in this paper). When $\mathrm{AC}$ was introduced alone, the maximum rate of heat evolution as well as the intensity of the main hydration peak remain almost the same as the reference sample. This indicates that when the effect of AC disappears, similar hydration reactions to CSA in the main hydration period took place.

PCE added with the same dosage, resulted in an extension of the CSA's induction period by almost 2 times. Compared to the reference, the PCE decreased the maximum rate of heat 
evolution and the intensity of the main hydration peak, which indicates that unlike the AC, the PCE changed the hydration kinetics during the whole hydration process of CSA.

When combining AC with PCE (dosage of $0.2 \mathrm{wt} \%$ each), the induction period was extended by almost 4 times compared to the reference sample, while the maximum rate of heat evolution and the intensity of the main hydration peak remain almost unchanged. Moreover, it can be seen that the heat flow curve of $0.2 \mathrm{AC}+0.2 \mathrm{PCE}$ overlaps with that of $0.2 \mathrm{AC}$ during the first $130 \mathrm{~min}$ of hydration. Thus, it seems that the hydration of $0.2 \mathrm{AC}+0.2 \mathrm{PCE}$ is mainly dictated by AC with only an additional delay induced by the PCE. However, the hydration delay induced by the combination of these two admixtures was not cumulative, indicating that a competition between AC and PCE may have occurred.

Fig. 2,b shows the influence of AC, PCE and their combination on the cumulative heat released. The latter was obtained by integrating the heat flow starting from 30 min after the hydration initiation. In general, the cumulative heat released is believed to be a good approximation of the hydration degree at early ages [37]. Thus, for the reference sample, the hydration progresses slowly during the first $50 \mathrm{~min}$. After that, the hydration increases significantly, before slowing down after around $10 \mathrm{~h}$. PCE, introduced alone, resulted in a deceleration of the hydration. The latter was strongly accelerated only after about $100 \mathrm{~min}$. The introduction of $\mathrm{AC}$ alone resulted in a more deceleration of the hydration compared to PCE, as the strong acceleration of hydration occurred only after around $130 \mathrm{~min}$. When combining AC with PCE, the degree of hydration was similar to that of $0.2 \mathrm{AC}$ up to $150 \mathrm{~min}$. After that, the hydration continued its slow progression, before accelerating after around 200 min. It is observed that the admixtures used seem to lead to lower the ultimate hydration degree as the cumulative heat released after $48 \mathrm{~h}$ was lowered. 


\subsection{Phase development: XRD and TG analysis}

XRD measurements were carried out to investigate the influence of AC, PCE and their combination on the evolution of anhydrous and hydrated phases during the hydration of CSA. Five major phases were identified on the diffraction patterns of CSA plotted in Fig. 3 : ye'elimite, anhydrite, ettringite, gypsum and bredigite. The Rietveld calculations made on these diffraction patterns show that during the hydration of CSA, the amount of ye'elimite and anhydrite decreases, while the amount of ettringite increases. This observation is consistent with the reaction pathway shown in Eq. (1). However, diffraction patterns do not show the presence of reflections related to $\mathrm{AH}_{3}$, indicating that probably only amorphous $\mathrm{AH}_{3}$ has been formed. The latter may be included in the Am phases, which we quantified using $40 \%$ of $\mathrm{ZnO}$ as an internal standard. The amount of these Am phases increased from 14\% present in the anhydrous CSA to almost $75 \%$ after $48 \mathrm{~h}$ of hydration. The nature of the hydrates constituting these Am phases cannot be exactly identified by XRD measurements, but literature reports that several phases like AFm and aluminum hydroxide $\left(\mathrm{AH}_{3}\right)$ could be included in these Am phases [37].

Gypsum was formed in small quantities during the first 60 min after the hydration initiation, and totally consumed to form ettringite, according to Eq. (2), after $90 \mathrm{~min}$ of hydration. The amount of bredigite stayed almost the same during the hydration of CSA, confirming the poor reactivity of this phase $[17,49]$. For minor crystalline phases, the amount of periclase $(\mathrm{MgO})$ stayed almost constant during the hydration ( $2 \%)$, while $\mathrm{C}_{12} \mathrm{~A}_{7}$ and $\mathrm{CaF}_{2}$ were totally consumed after only 30 min of hydration. 


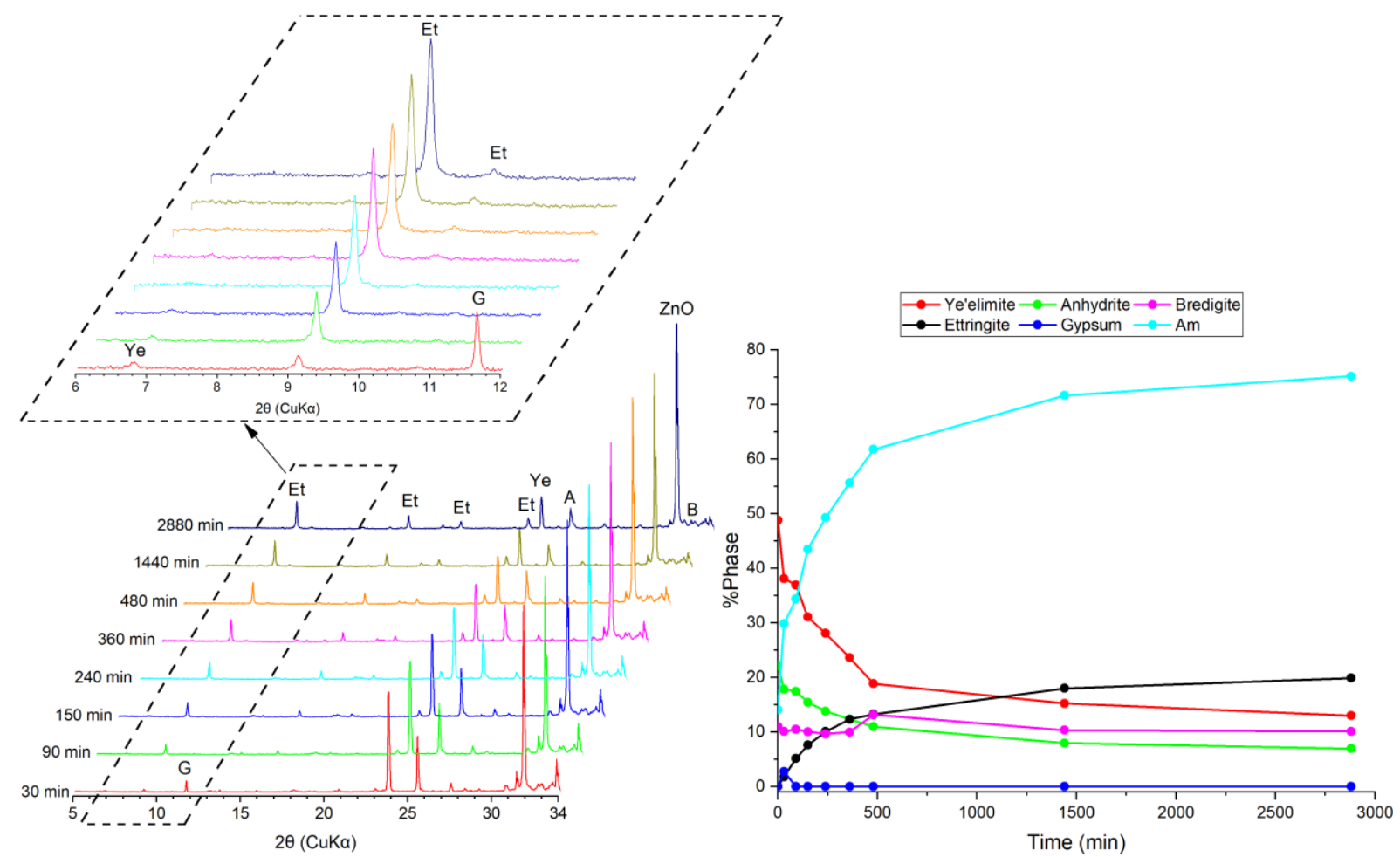

Fig. 3 diffraction patterns of CSA after several times of hydration (left); phase evolution during the hydration of CSA (right). Et: ettringite, G: gypsum, Ye: ye'elimite, A: anhydrite, B: bredigite

Diffraction patterns as well as the evolution of anhydrous and hydrated phases of $0.2 \mathrm{AC}$, 0.2PCE and 0.2AC + 0.2PCE are shown in Fig. 4, Fig. 5 and Fig. 6 respectively. Compared to the reference sample, these admixtures changed the kinetics of hydration by changing the dissolution of anhydrous phases as well as the precipitation of hydrated phases in a different way for each admixture. This will be discussed later in this paper. However, it seems that the admixtures used did not affect the amount, nor the reactivity of bredigite. 


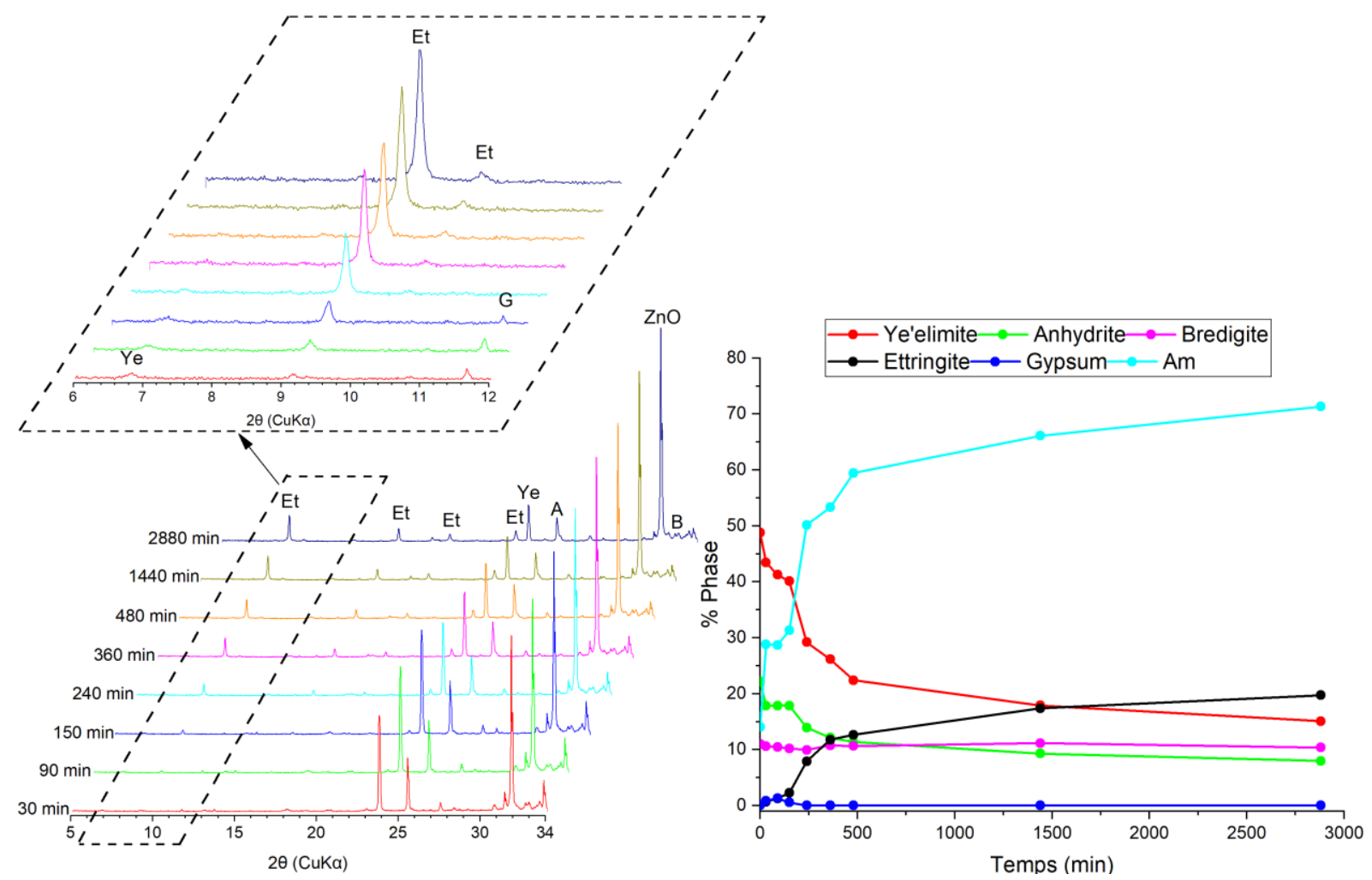

Fig. 4 diffraction patterns of 0.2AC after several times of hydration (left) ; phase evolution during the hydration of 0.2AC (right). Et: ettringite, G: gypsum, Ye: ye'elimite, A: anhydrite, B: bredigite 


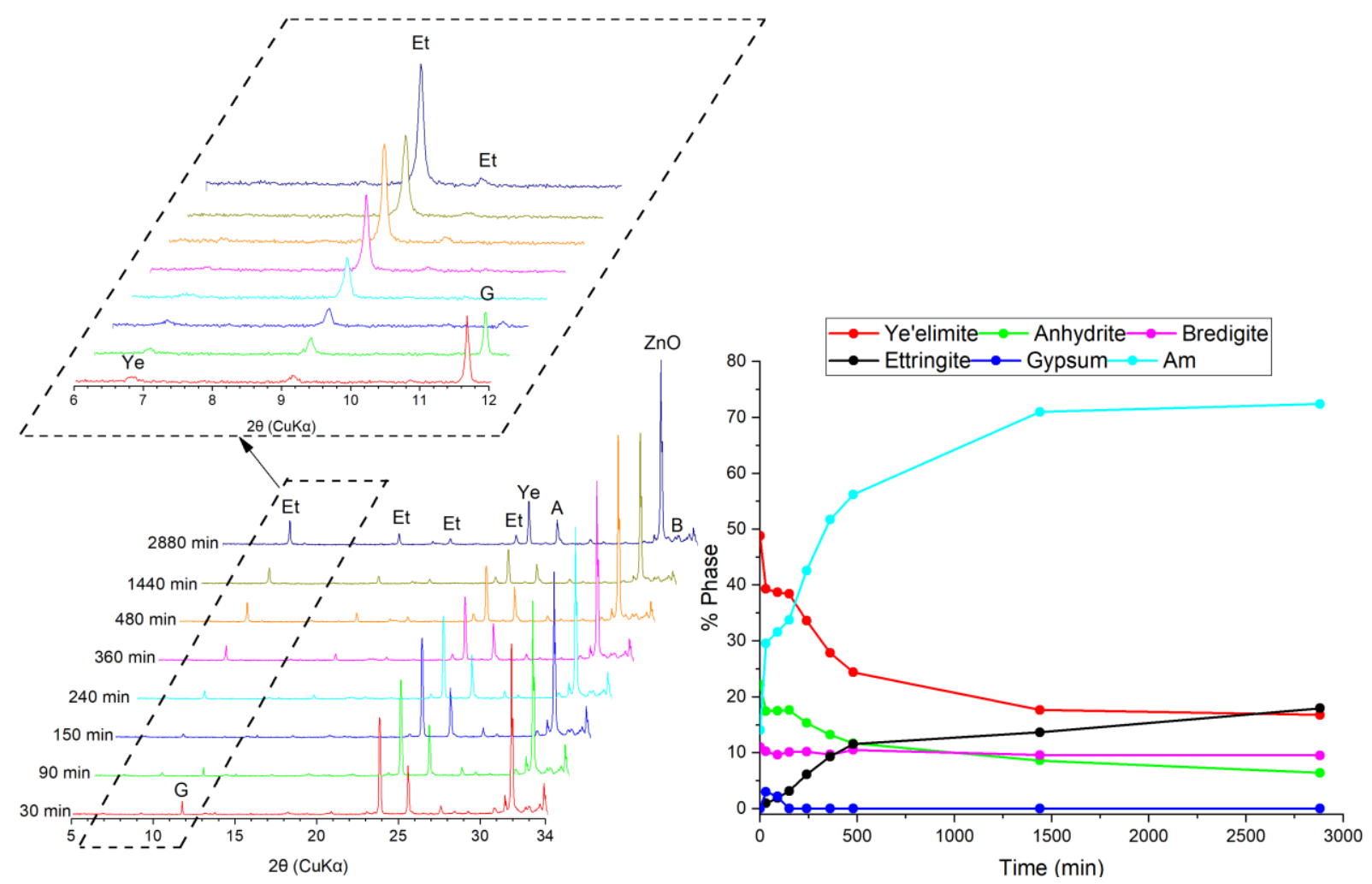

Fig. 5 diffraction patterns of $0.2 \mathrm{PCE}$ after several times of hydration (left) ; phase evolution during the hydration of 0.2PCE (right). Et: ettringite, G: gypsum, Ye: ye'elimite, A: anhydrite, B: bredigite 


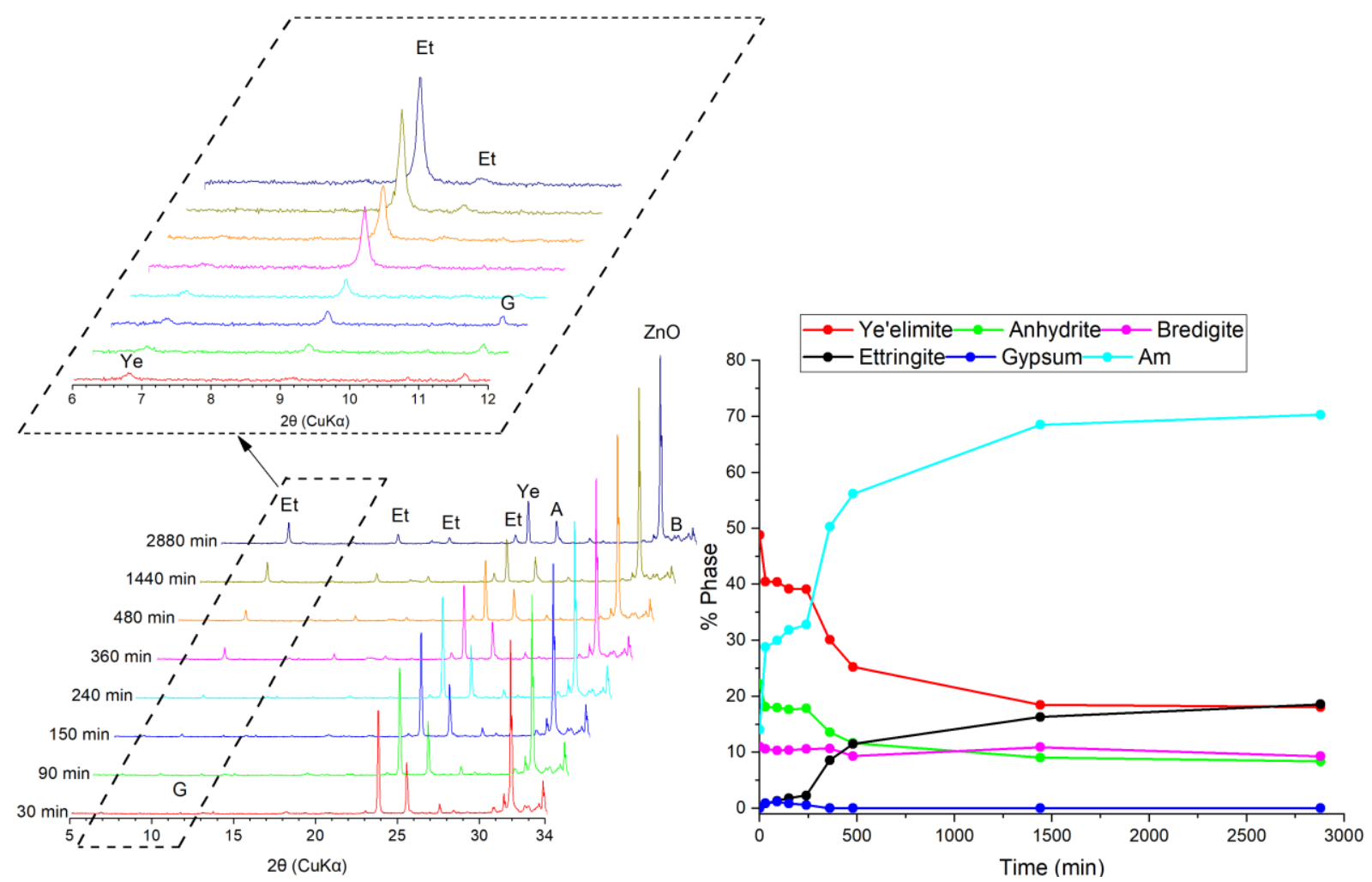

Fig. 6 diffraction patterns of 0.2AC + 0.2PCE after several times of hydration (left) ; phase evolution during the hydration of $0.2 \mathrm{AC}+0.2 \mathrm{PCE}$ (right). Et: ettringite, G: gypsum, Ye: ye'elimite, A: anhydrite, B: bredigite

For comparison, the evolution of the amount of anhydrous and hydrated phases of CSA, 0.2AC, $0.2 \mathrm{PCE}$ and $0.2 \mathrm{AC}+0.2 \mathrm{PCE}$ during the first $500 \mathrm{~min}$ of hydration were plotted in Fig. 7. It can be seen that during the initial period of hydration (the first $30 \mathrm{~min}$ of hydration), already $10.5 \%$ of ye'elimite and $5.5 \%$ of anhydrite were consumed in the reference sample. This rapid dissolution leaded to the formation of $1.8 \%$ of ettringite and an increase of the amount of Am to $30 \%$, which indicates that at least $16 \%$ of hydrated Am phases were formed during this initial period. Compared to the reference sample, the introduction of PCE alone do not seem to affect the initial dissolution of ye'elimite, while the use of AC alone resulted in a decrease of the initial dissolution of ye'elimite, as only 5.5\% was dissolved instead of $10.5 \%$ for the reference sample. When combining AC with PCE, a slight decrease of the initial 
dissolution of ye'elimite, compared to the reference sample, was seen. This observation is consistent with the assumption of competition between AC and PCE. In terms of ettringite formation, all the admixtures used, reduced slightly the amount of ettringite initially formed by almost the same quantity. The initial dissolution of anhydrite as well as the initial increase of the amount of Am phases were not affected by the introduction of these admixtures.
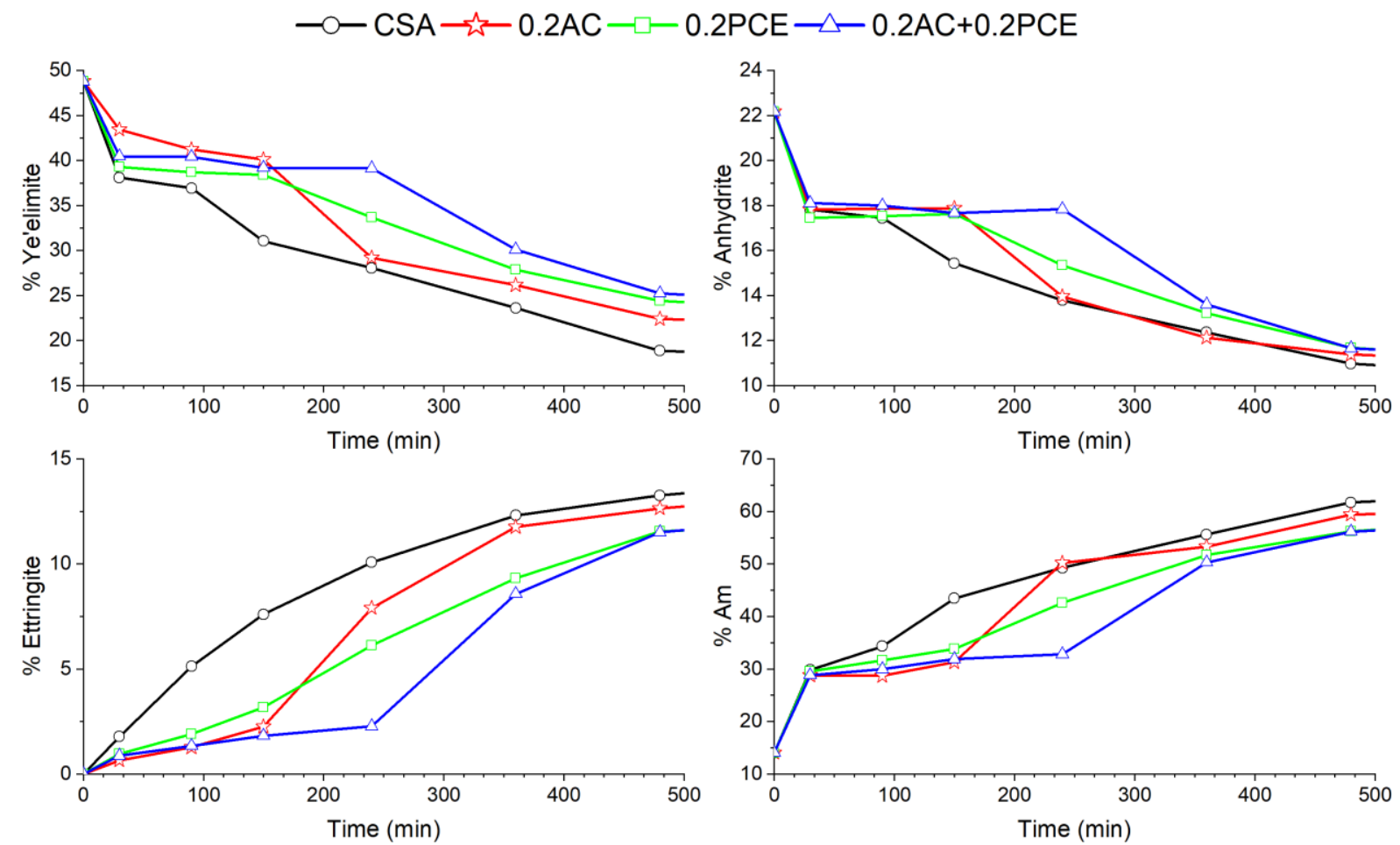

Fig. 7 Evolution of the amount of anhydrous and hydrated phases of CSA, influenced by AC, PCE and their combination. Results were derived from the Rietveld calculations. The dosage of admixtures was fixed at $0.2 \mathrm{wt} \%$.

For pure CSA, a period of a low activity ranging from 30 to 90 min of hydration, was noticed. This period was marked by the decrease of the ye'elimite and anhydrite dissolution, the decrease of the Am precipitation, and the continued increase of the amount of ettringite formed. This period is likely corresponding to the induction period determined by calorimetry measurements. The differences in the time of these periods could be related to the differences 
of the temperature of both experiments $\left(20^{\circ} \mathrm{C}\right.$ for XRD measurements, versus $25^{\circ} \mathrm{C}$ for calorimetry). The introduction of AC or PCE resulted in an extension of this period to 150 min. The latter was further extended to 240 min when combining AC with PCE.

During the induction period of $0.2 \mathrm{AC}$, around 3\% of ye'elimite was consumed, while the amount of anhydrite and Am phases stayed almost constant. Ettringite continued to form slowly to reach around $2.2 \%$. PCE, during the same period, resulted in a blockage of the dissolution of ye'elimite and anhydrite. The amount of ettringite reached for 0.2PCE (around $3.2 \%$ ) was slightly higher than that of $0.2 \mathrm{AC}$. When combining AC with PCE, the amount of all phases was almost blocked during the period of slow activity of $0.2 \mathrm{AC}+0.2 \mathrm{PCE}$.

Afterwards, an acceleration period takes place. The beginning of this period was marked by a reacceleration of ye'elimite and anhydrite dissolution. In the meantime, a reacceleration of ettringite and Am formation was seen. The reacceleration was faster for $0.2 \mathrm{AC}$ compared to 0.2PCE. The phase composition of the former almost reached that of the reference after $8 \mathrm{~h}$ of hydration, while the phase composition of $0.2 \mathrm{PCE}$ evolved slowly without reaching that of the reference. This observation is consistent with the results of calorimetry measurements, according to which PCE delayed the hydration kinetics during the whole hydration process of CSA, while $0.2 \%$ of AC delayed the hydration kinetics mainly by extending the induction period. When combining AC with PCE, the reacceleration only started after $4 \mathrm{~h}$ of hydration. The phase composition of $0.2 \mathrm{AC}+0.2 \mathrm{PCE}$ evolved quickly to reach that of $0.2 \mathrm{PCE}$, indicating a greater and longer decrease of the dissolution of anhydrous phases as well as the precipitation of hydrates.

Diffraction patterns do not show the development of monosulfate or the transformation of ettringite to monosulfate as suggested by several authors $[23,25,59]$. This could be related: (i) to the difficulties in detection of monosulfate by XRD due to several parameters like poor crystallinity, small crystallite size, strong preferred orientations or stacking faults [25,61], or 
(ii) to the non-formation of monosulfate due to the presence of sufficient amount of calcium sulfate to fulfill the sulfate requirements of Eq. (1) and/or Eq. (2). Indeed, a sulfate-toye'elimite molar ratio higher than 2 is required for the unique formation of ettringite during the hydration of ye'elimite. Otherwise, the hydration of ye'elimite will lead to a simultaneous formation of ettringite and monosulfate according to Eqs. (1) and (3).

In order to verify the second hypothesis, we plotted the evolution of the $\%_{\text {molar }}$ of anhydrite as a function of the $\%$ molar of ye'elimite during the first $48 \mathrm{~h}$ of hydration for CSA, 0.2AC, 0.2PCE and 0.2AC + 0.2PCE in Fig. 8. As it can be seen, the anhydrite-to-ye'elimite molar ratio remained slightly higher than 2 during the first $48 \mathrm{~h}$ of hydration of all our samples, which seems to suggest that only ettringite should be formed. However, this is true if only Eq. (1) occurred with respect to its stoichiometric coefficient.
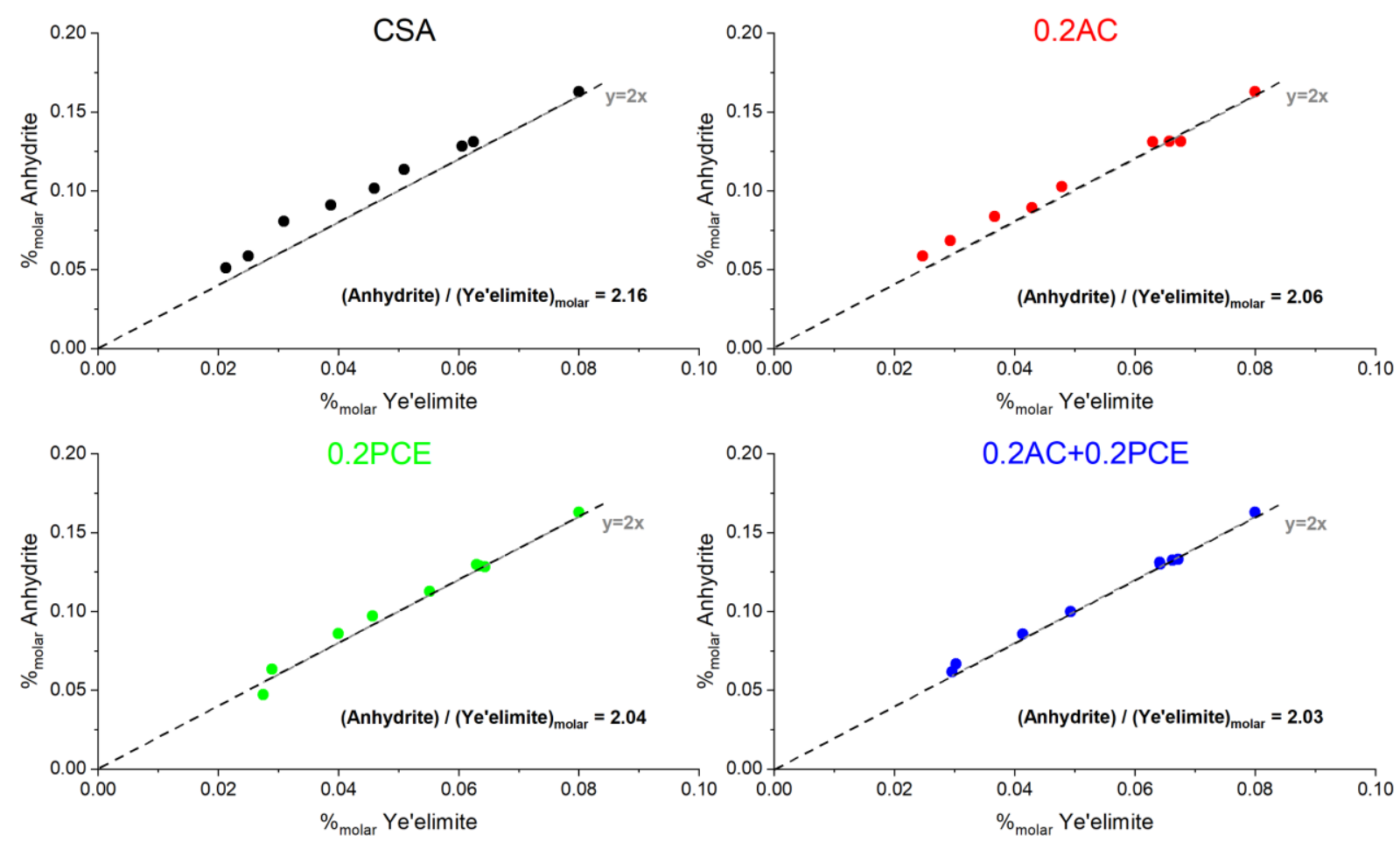

Fig. 8 Evolution of the molar amount of anhydrite as a function of that of ye'elimite 
Fig. 9 plots the molar amount of ye'elimite and anhydrite consumed, as well as that of ettringite formed during the hydration. Note that the molar amount of anhydrite consumed was divided by 2 in order to take into account the stoichiometric coefficients of Eq. (1). Thus, if Eq. (1) occurred with respect to its stoichiometric coefficients, the curves presented should overlap. As it can be seen, the (ye'elimite consumed)-to-(anhydrite consumed) molar ratio was almost equal to 2 during the hydration, indicating that the dissolution of ye'elimite and anhydrite may have followed the pathway of the Eq. (1). However, the curve of ettringite did not overlap with the other curves, indicating an ettringite deficit according to Eq. (1). Such results could be related to:

- A partial decomposition of ettringite due to the hydration stoppage. Literature reports that 5 to $10 \%$ of ettringite could be decomposed as a result of hydration stoppage using isopropanol as a solvent exchange [56]. However, we assume that such decomposition, if present, is not responsible for the low (ettringite formed)-to(ye'elimite consumed) molar ratio noticed (around 0.3 for all the samples).

- An underestimation of the amount of ettringite due to the high amount of internal standard introduced (40\%). This assumption was verified by introducing only $20 \%$ of $\mathrm{ZnO}$ instead of $40 \%$. Similar results were found, indicating that the amount of internal standard did not affect, significantly, the quantification of the ettringite formed.

- A formation of kinetically favored hydrates. This assumption is strengthened by the great amount of Am formed during the hydration.

Similar observations were found when treating the results of Zajac et al. [37], where an (ettringite formed)-to-(ye'elimite consumed) molar ratio of 0.6 and 0.3 were found when investigating the hydration of a CSA clinker blended with $10 \%$ of anhydrite and a CSA clinker without anhydrite respectively. Therefore, we cannot exclude the presence of monosulfate despite an anhydrite-to-ye'elimite molar ratio slightly higher than 2 . 

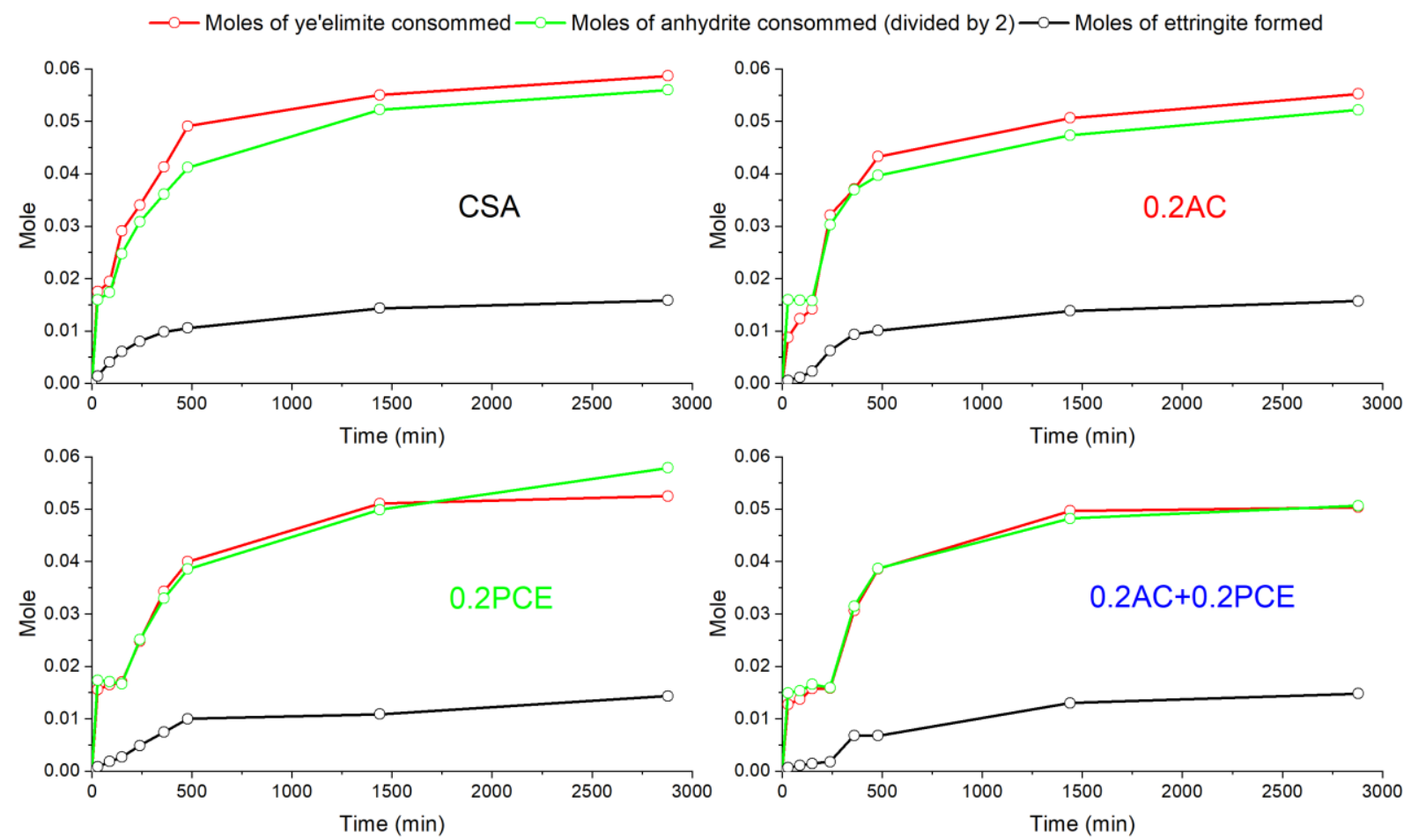

Fig. 9 Results from the Rietveld calculations plotted in moles. The molar amount of anhydrite consumed was divided by 2

Thermal analyses were made to supplement the XRD measurements and potentially determine which hydrates were formed, particularly the amorphous ones. The results are plotted in Fig. 10. For the reference, all the collected samples revealed a first weight loss from approximately $60{ }^{\circ} \mathrm{C}$ up to $120^{\circ} \mathrm{C}$, which may correspond to the decomposition of ettringite [56]. Additionally, the first sample collected after $30 \mathrm{~min}$ of hydration shows a second weight loss peaked at around $140{ }^{\circ} \mathrm{C}$. This peak seems to originate from the decomposition of gypsum. From about 90 min of hydration, a broad weight loss between $200{ }^{\circ} \mathrm{C}$ and $300{ }^{\circ} \mathrm{C}$, was remarked and could be related to the decomposition of $\mathrm{AH}_{3}$, which is known to lose its water at around $270{ }^{\circ} \mathrm{C}$ [56]. DTG curves do not show the presence of monosulfate, which thus confirms the non-formation of this phase during the first $48 \mathrm{~h}$ of hydration. 

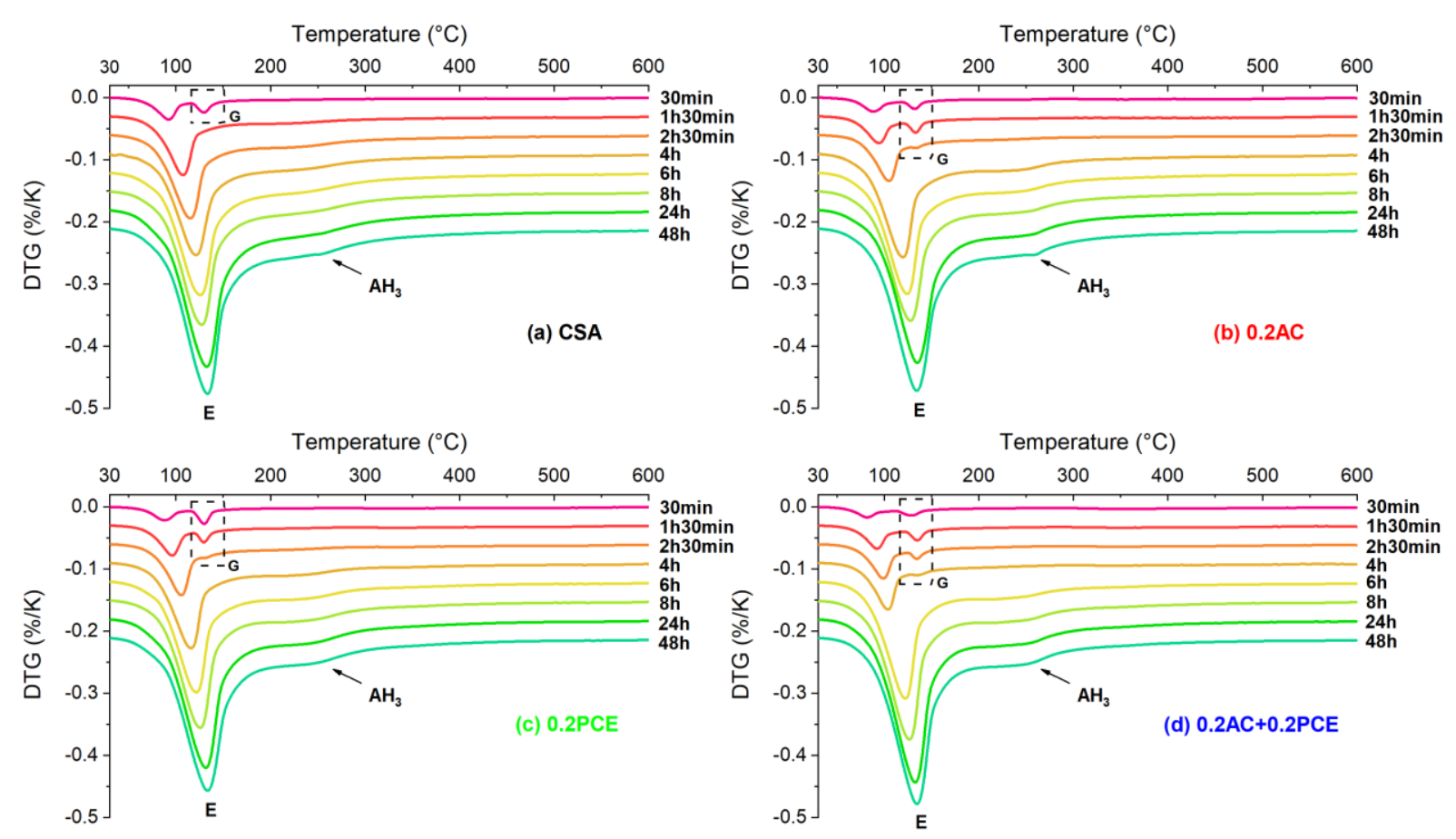

Fig. 10 DTG curves of CSA, 0.2AC, 0.2PCE and 0.2AC+0.2PCE after several times of hydration. E : ettringite; G : gypsum

The evolution of the amount of the identified phases over time is shown in Fig. 11. The admixtures used decreased the formation of ettringite in the same way as described for XRD analysis. However, TG seems to overestimate the amount of ettringite formed compared to XRD. This suggests that a part of the Am phases determined, could decompose in the same temperature range as ettringite.

The admixtures used decreased the consumption of gypsum during the hydration, and the evolution of the amount of $\mathrm{AH}_{3}$ follows almost the same trends as the evolution of the amount of ettringite, which is consistent with the pathway of Eq. (1). However, the molar balance indicates that the $\left(\mathrm{AH}_{3}\right.$ determined by TG)-to-(ettringite determined by XRD) molar ratio of all samples was almost equal to 8 , which is higher than what should be expected according to Eq. (1). On the contrary, the $\left(\mathrm{AH}_{3}\right.$ determined by TG)-to-(ye'elimite consumed and 
determined by XRD) molar ratio (around 2.32) was consistent with the stoichiometric coefficients of Eq. (1). Therefore, ye'elimite may have been consumed to form $\mathrm{AH}_{3}$ according to other reactions than the one presented by Eq. (1).
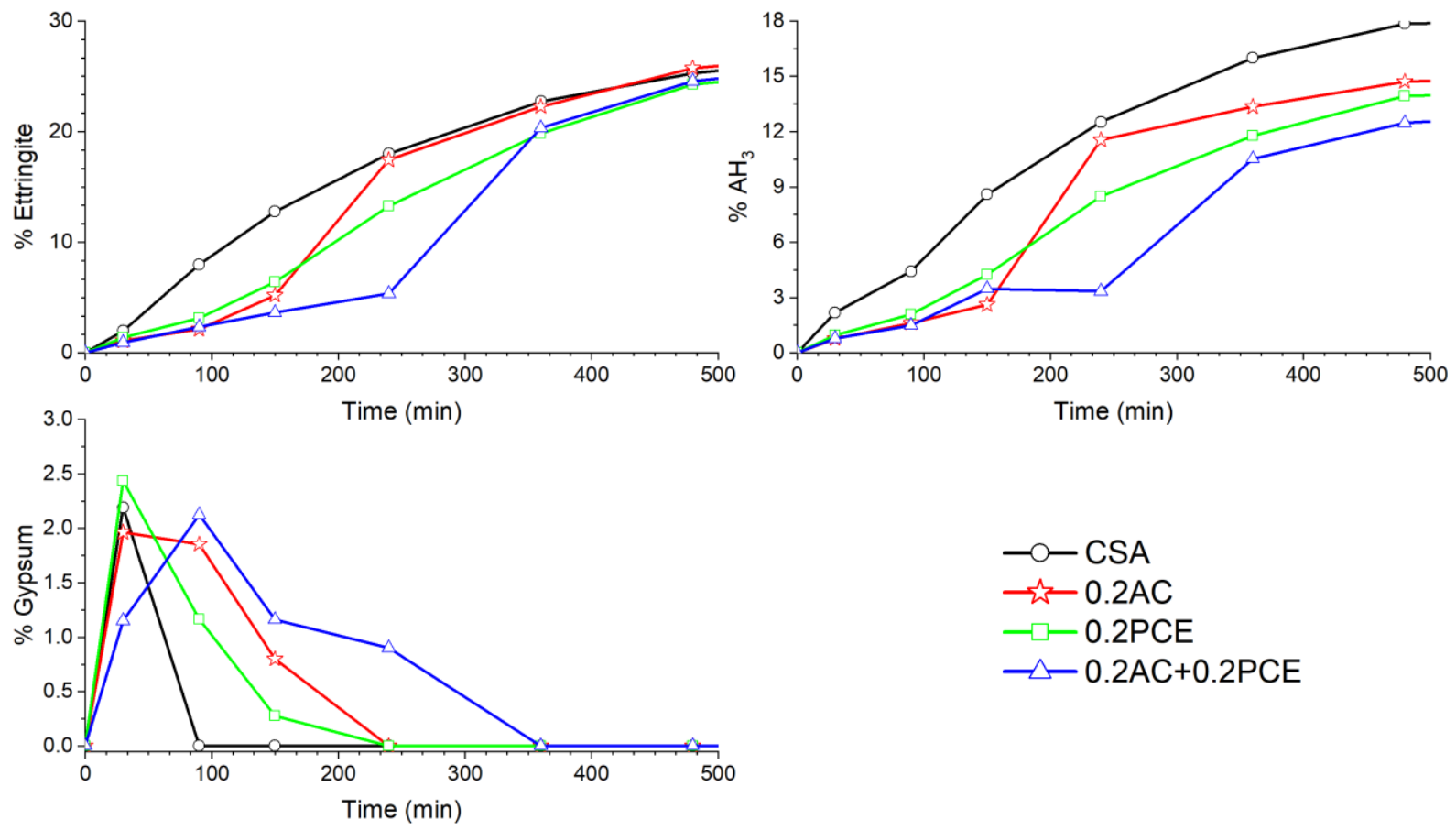

Fig. 11 Evolution of the amount of hydrated phases of CSA, influenced by AC, PCE and their combination

\subsection{Flow characterization of cement pastes}

The influence of PCE, AC and their combination on the workability of CSA is discussed based on the evolution of the yield stress of the pastes. The latter was derived from the diameter of the spread paste, using the formula developed by Zimmermann et al. [62]:

$$
\tau_{0}=\frac{225 \rho g V^{2}}{128 \pi^{2} R^{5}\left(1+225 / 128 \pi \sqrt{3} V R^{-3}\right)}-\lambda \times \frac{R^{2}}{V}
$$


Where, $\tau_{0}=$ the yield stress of the paste, $\rho=$ paste density, $\mathrm{V}=$ volume of the cone, $\mathrm{R}=$ radius of the spread paste and $\lambda$ is a constant linked to the liquid vapor interfacial energy and the wetting angle on the plate. In this paper, $\lambda$ was fixed at 0.003 [63].

The evolution of the yield stress, as a function of time, for CSA pastes made with or without admixtures (PCE and/or AC) at a dosage of $0.2 \mathrm{wt} \%$ is shown in Fig. 12. The yield stress was plotted in both linear and log scale. The latter allows a better visualization of the influence of the admixtures used on the evolution of the yield stress. Therefore, the following discussion will be focused on Fig. 12,b. Without admixtures, the yield stress of CSA is above $200 \mathrm{~Pa}$ after only $8 \mathrm{~min}$ of hydration, which shows the poor workability of this type of cement. At a dosage of $0.2 \mathrm{wt} \%$, the PCE decreased significantly the initial yield stress (at $8 \mathrm{~min}$ of hydration) to $0.5 \mathrm{~Pa}$. However, a fast loss of workability over time, characterized by a fast increase of the yield stress, was remarked. These results confirm the observations made by Winnefeld [24], according to which the workability of CSA pastes, containing PCE, drops quickly over time despite a relatively higher initial fluidity. This may be attributed to the fast hydration of CSA, which leads to the consumption of PCE by the massive formation of hydrates $[22,24,36]$.

The influence of AC added with the same dosage results in a slight decrease in the initial yield stress $(\approx 100 \mathrm{~Pa})$. However, the increase of the yield stress over time was slower than that of paste containing PCE alone.

When combining AC with PCE (dosage of $0.2 \mathrm{wt} \%$ each), the paste exhibits an initial yield stress of $10 \mathrm{~Pa}$, which is higher than that of PCE alone. Thus, AC decreases the initial dispersive effect of PCE, indicating that a competition between AC and PCE may have occurred. After 8 min, the yield stress starts to decrease to reach a minimum almost equal to the initial yield stress of paste containing PCE alone $\left(\tau_{0} \approx 0.5 \mathrm{~Pa}\right)$ at approximately $38 \mathrm{~min}$. 
Afterwards, the yield stress began to increase slowly over time to reach its maximum after 200 min. This indicates that the combination of AC with PCE retained the dispersive effect of PCE over time.

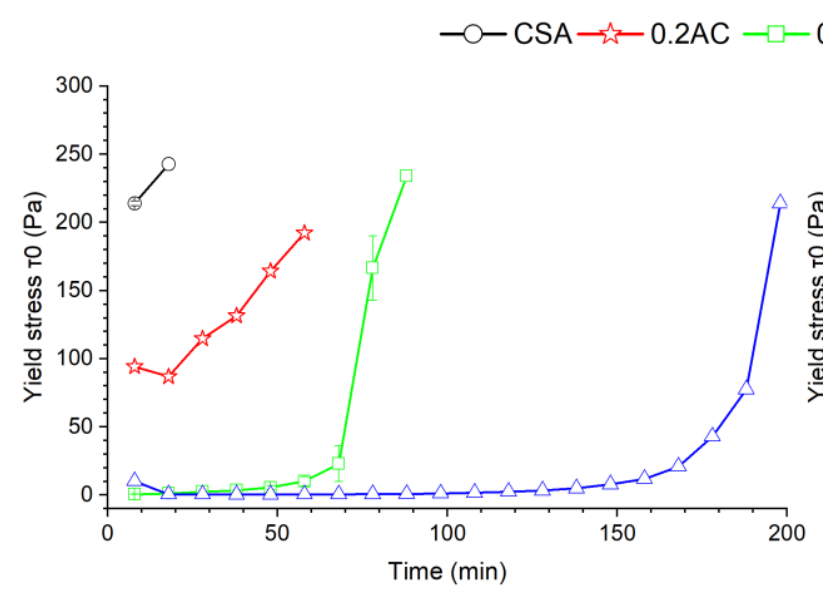

(a)

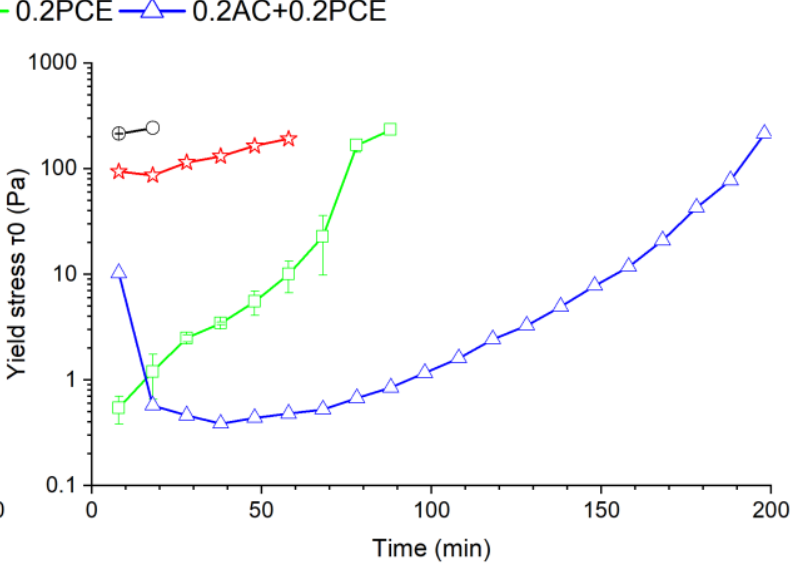

(b)

Fig. 12 Evolution of the yield stress of the investigated samples : (a) linear scale ; (b) log scale

\subsection{Adsorption measurements}

It has been well documented that the dispersion efficiency of PCE in cementitious materials is strongly dependent on its adsorption on the surface of cement grains $[35,64]$. Therefore, the adsorption of PCE was quantified with and without the presence of AC. Fig. 13 shows the evolution, within time, of the adsorbed amount of PCE and AC in PCE-system, AC-system and AC + PCE-system. When introduced alone, AC revealed a high initial adsorption capacity ( $\approx 97 \%$ at $8 \mathrm{~min}$ of hydration) compared to PCE $(\approx 35 \%$ at $8 \mathrm{~min}$ of hydration). The adsorption of AC quickly converged to $100 \%$, while the adsorption of PCE increased slowly over time and only reached around $43 \%$ after 38 min of hydration.

The presence of $\mathrm{AC}$ resulted in a strong decrease of the initial adsorption of PCE (from 35\% to less than $10 \%$ ), which thus could explain the higher initial yield stress of $0.2 \mathrm{AC}+0.2 \mathrm{PCE}$ compared to 0.2PCE as shown in Fig. 12,b. In the meantime, the presence of PCE resulted in 
a slight decrease in the initial adsorption of AC (from 97\% to 87\%). Since all the investigated samples presented relatively the same amount of hydrates formed at $8 \mathrm{~min}$ (Fig. 7), the decrease in the initial adsorption of PCE is likely due to the decrease in the number of available adsorption sites, which were initially occupied by AC. The latter has the ability to adsorb first on the surface of the cement grains and initial hydration products due to its higher charge density, smaller molecules size and higher mobility compared to PCE. Moreover, the decrease of the initial adsorption of $\mathrm{AC}$ in the presence of PCE indicates that these two admixtures competed for adsorption sites. This finding is in good agreement with the observations of Plank and Winter [46], according to which the high charge density of AC enhances its rapid adsorption, hindering the adsorption of PCE.

After $8 \mathrm{~min}$, the adsorption of $\mathrm{AC}$ in the $0.2 \mathrm{AC}+0.2 \mathrm{PCE}$ system increased quickly over time to reach $100 \%$ after around 40 min of hydration, while the adsorption of PCE in the same system increased slowly over time, reaching a value of around $34 \%$ after $118 \mathrm{~min}$. In $0.2 \mathrm{AC}+$ 0.2PCE system, the increase of the adsorption of PCE over time as well as the delay of hydration induced by the presence of AC could explain the continuous decrease of the yield stress during the first 38 min of hydration, and then the retaining of workability over time (Fig. 12,b). 


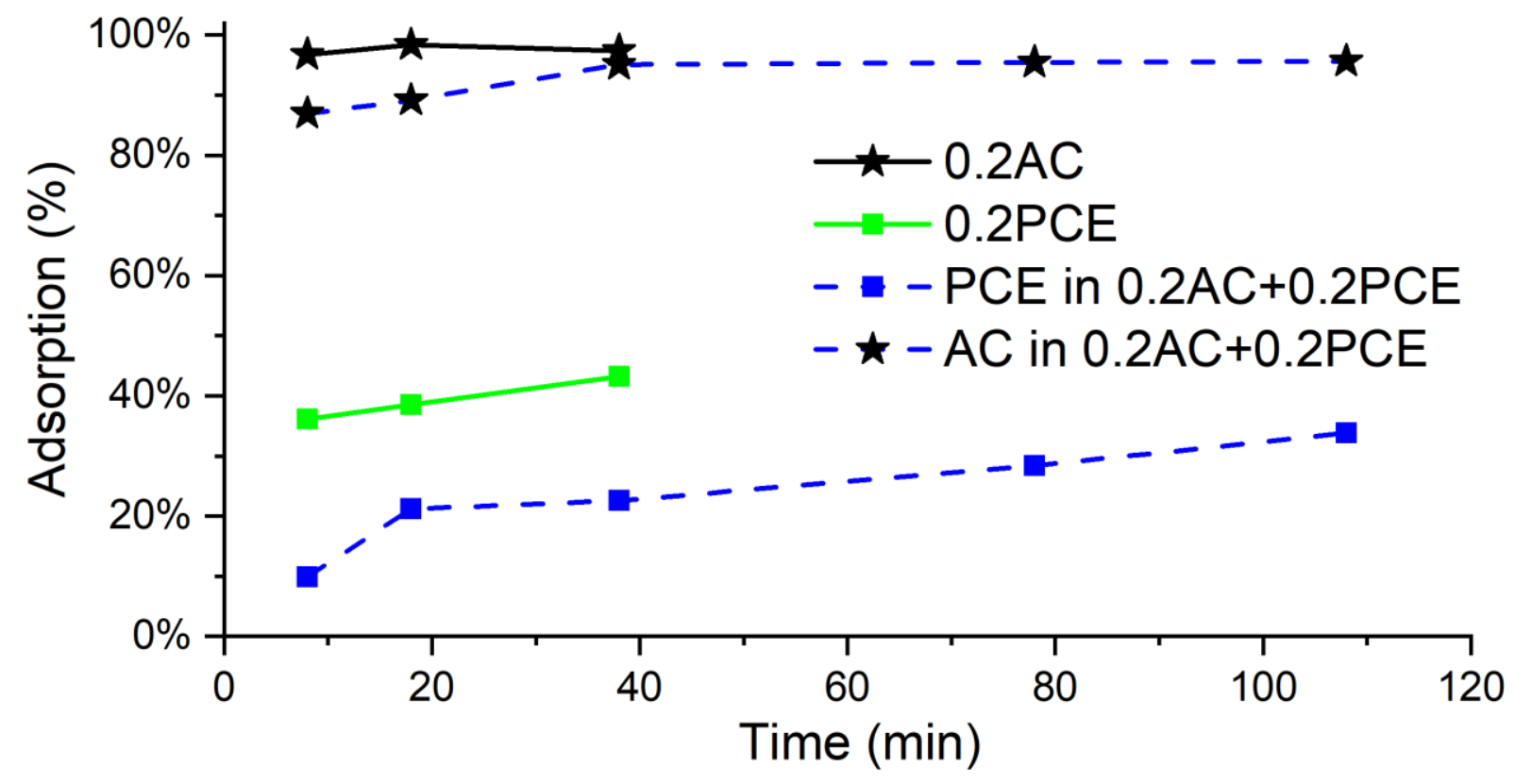

Fig. 13 Evolution of the adsorption of AC and PCE in the investigated samples. An average error of $\pm 0.5 \%$ was determined.

\subsection{Dispersion model}

Based on the results of this study, the following interaction mechanisms in the CSA containing AC and/or PCE is proposed:

When PCE is added alone, a part of the PCE is initially adsorbed on the surface of cement grains and initial hydration products. The non-charged side chains exhibit repulsive forces between cement particles through steric hindrance [34,35], resulting in the dispersion of cement grains and thus the increase of the initial fluidity. As the hydration progresses, hydrates will be formed and partly covered the PCE's side chains $[36,65]$ as shown in Fig. 14. The covered side chains are no longer available for the dispersion, resulting in the loss of dispersion efficiency of the PCE over time. In the meantime, the PCE remaining initially in the pore solution will continue to adsorb gradually on the surface of hydrates to induce steric repulsion. Therefore, the dispersion efficiency of PCE at a certain time lies on the uncovered 
side chains at this time. The quick loss of dispersion efficiency of PCE with CSA is attributed to the fast hydration of CSA.

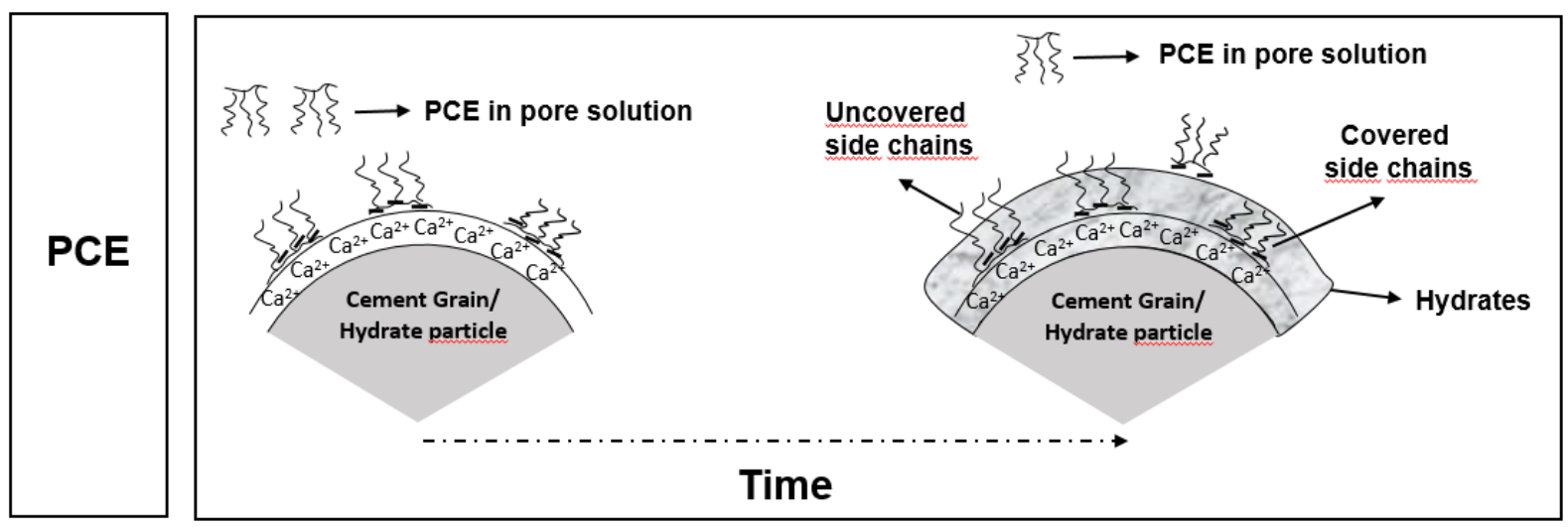

Fig. 14 Acting mechanism of PCE

When $\mathrm{AC}$ is incorporated alone, the carboxylate groups $\left(-\mathrm{COO}^{-}\right)$of $\mathrm{AC}$ bind with $\mathrm{Ca}^{2+}$ to form highly charged complexes $\left[\mathrm{Ca}(\text { citrate })_{2}\right]^{4-}[41]$ that adsorb on the surface of cement grains, forming a calcium-base citrate layer $[32,60]$. This layer prevents the dissolution of ye'elimite and anhydrite as well as the precipitation of ettringite, inducing a hydration delay of CSA. The decrease of yield stress induced by AC could be explained by the decrease of the rate of hydrates formation, which implies a decrease in the coagulation rate of hydrates.

The combination of AC with PCE results in the immediate adsorption of $\left[\mathrm{Ca}(\text { citrate })_{2}\right]^{4-}$ complexes on the surface of cement grains due to their high charge density and mobility. Therefore, the initial adsorption of PCE was lowered as shown in Fig. 13 and illustrated in Fig. 15, resulting in a decrease in the initial dispersion efficiency of the PCE (Fig. 12). As hydration progresses, the amount of hydrates formed was lowered by the presence of AC, while the adsorption of PCE increased slowly over time as shown in Fig. 13. Thus, less side chains will be covered by hydrates, which leads to maintain the dispersing efficiency of the PCE over time. 


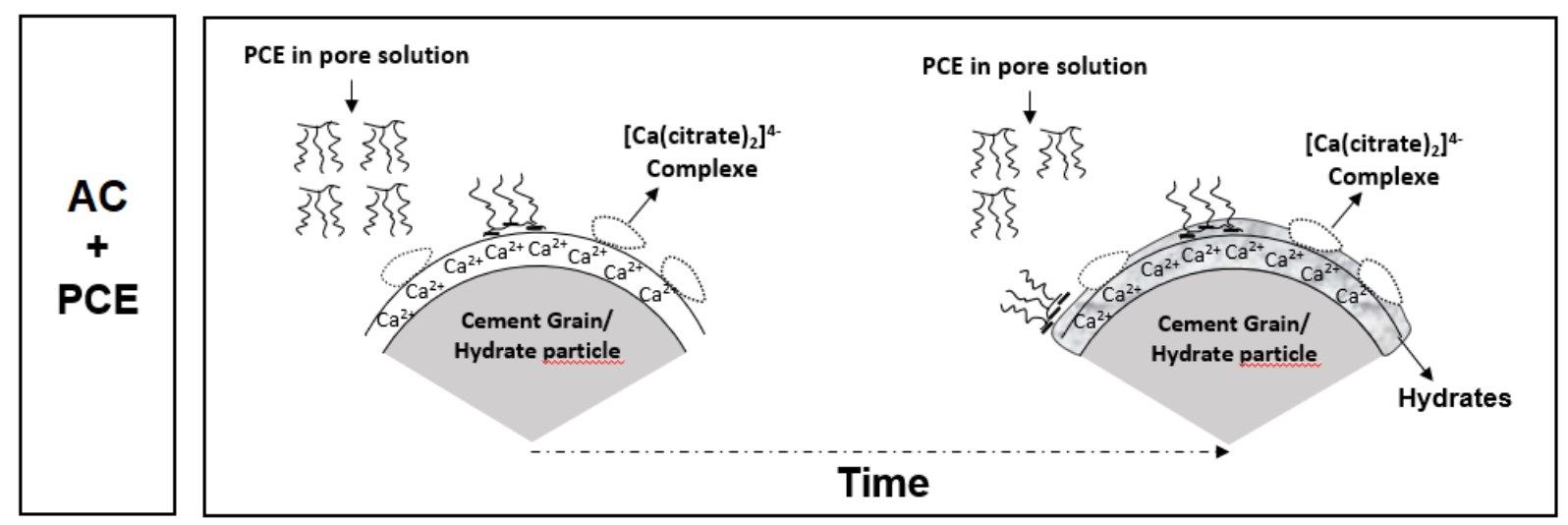

Fig. 15 Acting mechanism of AC+PCE

\section{Conclusion}

In order to extend the use of sulfoaluminate cements to larger-scale applications, the influence of PCE, AC and their combination on the hydration and rheology of a commercially available CSA was examined. For that, yield stress, hydration kinetics, CSA's phase development and adsorption of admixtures were examined.

PCE was found to be effective in increasing the initial fluidity of CSA. However, PCE quickly loses its dispersion efficiency over time due to the massive formation of hydrates that covered their side chains. The introduction of AC combined with PCE resulted in a decrease of the quick loss of the dispersion efficiency of PCE over time. AC was found to induce a hydration delay, mainly by preventing the dissolution of ye'elimite and anhydrite, and the formation of ettringite and Am phases. Thus, the consumption of PCE by hydrates was lowered, permitting the maintain of the dispersion efficiency of the PCE over time. However, the initial fluidity was decreased due to the competitive adsorption between AC and PCE. Thanks to its high charge density and mobility, calcium-base citrate adsorbs instantly on the surface of cement grains and hinders partly the adsorption of PCE. 


\section{Acknowledgement}

The authors would like to acknowledge Chryso and Calcia for the PCE and CSA they provided, respectively.

\section{References}

[1] IEA, Technology Roadmap - Low-Carbon Transition in the Cement Industry, IEA, Paris, 2018. https://www.iea.org/reports/technology-roadmap-low-carbon-transition-inthe-cement-industry.

[2] E.M.G. Karen L. Scrivener, Vanderley M. John, Eco-efficient cements: Potential, economically viable solutions for a low-CO2, cement- based materials industry, 2016. https://doi.org/978-3-940388-48-3.

[3] M.C.G.G. Juenger, F. Winnefeld, J.L. Provis, J.H. Ideker, Advances in alternative cementitious binders, Cem. Concr. Res. 41 (2011) 1232-1243. https://doi.org/10.1016/j.cemconres.2010.11.012.

[4] E. Gartner, Industrially interesting approaches to "low-CO2" cements, Cem. Concr. Res. 34 (2004) 1489-1498. https://doi.org/10.1016/j.cemconres.2004.01.021.

[5] J.S. Damtoft, J. Lukasik, D. Herfort, D. Sorrentino, E.M. Gartner, Sustainable development and climate change initiatives, Cem. Concr. Res. 38 (2008) 115-127. https://doi.org/10.1016/j.cemconres.2007.09.008.

[6] J.G.J. Olivier, G. Janssens-Maenhout, J. a H.W. Peters, Trends in global CO2 emissions: 2012 Report, 2012.

[7] A. Rahman, M.G. Rasul, M.M.K. Khan, S. Sharma, Recent development on the uses of alternative fuels in cement manufacturing process, Fuel. 145 (2015) 84-99. https://doi.org/10.1016/j.fuel.2014.12.029. 
[8] C. Horsley, M.H. Emmert, A. Sakulich, Influence of alternative fuels on trace element content of ordinary portland cement, Fuel. 184 (2016) 481-489. https://doi.org/10.1016/j.fuel.2016.07.038.

[9] M. Ben Haha, B. Lothenbach, G. Le Saout, F. Winnefeld, Influence of slag chemistry on the hydration of alkali-activated blast-furnace slag - Part II: Effect of Al2O3, Cem. Concr. Res. 42 (2012) 74-83. https://doi.org/10.1016/j.cemconres.2011.08.005.

[10] F. Lavergne, R. Belhadi, J. Carriat, A. Ben Fraj, Effect of nano-silica particles on the hydration, the rheology and the strength development of a blended cement paste, Cem. Concr. Compos. 95 (2019) 42-55. https://doi.org/10.1016/j.cemconcomp.2018.10.007.

[11] J.L. Provis, Alkali-activated materials, Cem. Concr. Res. 114 (2018) 40-48. https://doi.org/10.1016/j.cemconres.2017.02.009.

[12] C.W. Hargis, A.P. Kirchheim, P.J.M. Monteiro, E.M. Gartner, Early age hydration of calcium sulfoaluminate (synthetic ye'elimite, C 4A3S) in the presence of gypsum and varying amounts of calcium hydroxide, Cem. Concr. Res. 48 (2013) 105-115. https://doi.org/10.1016/j.cemconres.2013.03.001.

[13] D. Zhang, B. Jaworska, H. Zhu, K. Dahlquist, V.C. Li, Engineered Cementitious Composites (ECC) with limestone calcined clay cement (LC3), Cem. Concr. Compos. 114 (2020). https://doi.org/10.1016/j.cemconcomp.2020.103766.

[14] S. Cloete, A. Giuffrida, M.C. Romano, A. Zaabout, The swing adsorption reactor cluster for post-combustion CO 2 capture from cement plants, J. Clean. Prod. 223 (2019) 692-703. https://doi.org/10.1016/j.jclepro.2019.03.109.

[15] A. Bosoaga, O. Masek, J.E. Oakey, CO2 Capture Technologies for Cement Industry, Energy Procedia. 1 (2009) 133-140. https://doi.org/10.1016/j.egypro.2009.01.020. 
[16] F.P. Glasser, L. Zhang, High-performance cement matrices based on calcium sulfoaluminate-belite compositions, Cem. Concr. Res. 31 (2001) 1881-1886. https://doi.org/10.1016/S0008-8846(01)00649-4.

[17] L.U.D. Tambara, M. Cheriaf, J.C. Rocha, A. Palomo, A. Fernández-Jiménez, Effect of alkalis content on calcium sulfoaluminate (CSA) cement hydration, Cem. Concr. Res. 128 (2020) 105953. https://doi.org/10.1016/j.cemconres.2019.105953.

[18] F. Bullerjahn, Characterisation and hydration of ye'elimite containing cements. PhD thesis, 2018.

[19] F. Winnefeld, L.H.J. Martin, C.J. Müller, B. Lothenbach, Using gypsum to control hydration kinetics of CSA cements, Constr. Build. Mater. 155 (2017) 154-163. https://doi.org/10.1016/j.conbuildmat.2017.07.217.

[20] M. García-Maté, A.G. De La Torre, L. León-Reina, E.R. Losilla, M.A.G. Aranda, I. Santacruz, Effect of calcium sulfate source on the hydration of calcium sulfoaluminate eco-cement, Cem. Concr. Compos. 55 (2015) 53-61. https://doi.org/10.1016/j.cemconcomp.2014.08.003.

[21] W. Lan, F.P. Glasser, Hydration of calcium sulphoaluminate cements, Adv. Cem. Res. 8 (1996) 127-134. https://doi.org/10.1680/adcr.1996.8.31.127.

[22] L. Zhang, F.P. Glasser, Hydration of calcium sulfoaluminate cement at less than 24 h, Adv. Cem. Res. 14 (2002) 141-155. https://doi.org/https://doi.org/10.1680/adcr.2002.14.4.141.

[23] F. Winnefeld, B. Lothenbach, Hydration of calcium sulfoaluminate cements Experimental findings and thermodynamic modelling, in: Cem. Concr. Res., Elsevier Ltd, Montreal, 2010: pp. 1239-1247. https://doi.org/10.1016/j.cemconres.2009.08.014. 
[24] F. Winnefeld, Interaction of Superplasticizers with Calcium sulfoaluminate Cements, in: Suppl. Pap. Tenth Int. Conf. Superplast. Other Chem. Admixtures Concr. Prague, Czech Republic, Oct., 2012: pp. 28-31.

[25] S.W. Tang, H.G. Zhu, Z.J. Li, E. Chen, H.Y. Shao, Hydration stage identification and phase transformation of calcium sulfoaluminate cement at early age, Constr. Build. Mater. 75 (2015) 11-18. https://doi.org/10.1016/j.conbuildmat.2014.11.006.

[26] L.E. Burris, K.E. Kurtis, Influence of set retarding admixtures on calcium sulfoaluminate cement hydration and property development, Cem. Concr. Res. 104 (2018) 105-113. https://doi.org/10.1016/j.cemconres.2017.11.005.

[27] T. Kuryatnyk, M. Chabannet, J. Ambroise, J. Pera, Leaching behaviour of mixtures containing plaster of Paris and calcium sulphoaluminate clinker, Cem. Concr. Res. 40 (2010) 1149-1156. https://doi.org/10.1016/j.cemconres.2010.03.013.

[28] T. Kuryatnyk, M. Chabannet, J. Ambroise, J. Pera, Improvement of calcium sulphate water resistance by addition of calcium sulphoaluminate clinker, Mater. Lett. 62 (2008) 3713-3715. https://doi.org/10.1016/j.matlet.2008.04.036.

[29] V. Albino, R. Cioffi, M. Marroccoli, L. Santoro, Potential application of ettringite generating systems for hazardous waste stabilization, J. Hazard. Mater. 51 (1-3) (1996) $241-252$.

[30] C.A. Luz, J.C. Rocha, M. Cheriaf, J. Péra, Use of sulfoaluminate cement and bottom ash in the solidification/stabilization of galvanic sludge, J. Hazard. Mater. 136 (3) (2006) 837-845.

[31] C. Cau Dit Coumes, S. Courtois, S. Peysson, J. Ambroise, J. Pera, Calcium sulfoaluminate cement blended with OPC: A potential binder to encapsulate low-level 
radioactive slurries of complex chemistry, Cem. Concr. Res. 39 (2009) 740-747. https://doi.org/10.1016/j.cemconres.2009.05.016.

[32] T. Sugama, Citric acid as a set retarder for calcium aluminate phosphate cements, (BNL-73600-2005-I), Brookhaven Natl. Lab. (2005). https://doi.org/10.1680/adcr.2006.18.2.47.

[33] R.J. Flatt, I. Schober, E. Raphael, C. Plassard, E. Lesniewska, Conformation of adsorbed comb copolymer dispersants, Langmuir. 25 (2009) 845-855. https://doi.org/10.1021/la801410e.

[34] H. Uchikawa, S. Hanehara, D. Sawaki, The role of steric repulsive force in the dispersion of cement particles in fresh paste prepared with organic admixture, Cem. Concr. Res. 27 (1997) 37-50. https://doi.org/10.1016/S0008-8846(96)00207-4.

[35] F. Winnefeld, S. Becker, J. Pakusch, T. Götz, Effects of the molecular architecture of comb-shaped superplasticizers on their performance in cementitious systems, Cem. Concr. Compos. 29 (2007) 251-262. https://doi.org/10.1016/j.cemconcomp.2006.12.006.

[36] H. Tan, Y. Guo, F. Zou, S. Jian, B. Ma, Z. Zhi, Effect of borax on rheology of calcium sulphoaluminate cement paste in the presence of polycarboxylate superplasticizer, Constr. Build. Mater. 139 (2017) 277-285. https://doi.org/10.1016/j.conbuildmat.2017.02.005.

[37] M. Zajac, J. Skocek, F. Bullerjahn, M. Ben Haha, Effect of retarders on the early hydration of calcium-sulpho-aluminate (CSA) type cements, Cem. Concr. Res. 84 (2016) 62-75. https://doi.org/10.1016/j.cemconres.2016.02.014.

[38] Y. Hu, W. Li, S. Ma, X. Shen, Influence of borax and citric acid on the hydration of 
calcium sulfoaluminate cement, Chem. Pap. 71 (2017) 1909-1919.

https://doi.org/10.1007/s11696-017-0185-9.

[39] C. Cau Dit Coumes, M. Dhoury, J.B. Champenois, C. Mercier, D. Damidot, Combined effects of lithium and borate ions on the hydration of calcium sulfoaluminate cement, Cem. Concr. Res. 97 (2017) 50-60. https://doi.org/10.1016/j.cemconres.2017.03.006.

[40] G. Zhang, G. Li, Y. Li, Effects of superplasticizers and retarders on the fluidity and strength of sulphoaluminate cement, Constr. Build. Mater. 126 (2016) 44-54. https://doi.org/10.1016/j.conbuildmat.2016.09.019.

[41] J.R. Hill, J. Plank, Retardation of setting of plaster of paris by organic acids: Understanding the mechanism through molecular modeling, J. Comput. Chem. 25 (2004) 1438-1448. https://doi.org/10.1002/jcc.20070.

[42] T.E. Zelenina, O.Y. Zelenin, Concentration and thermodynamic stability constants of magnesium(II) and calcium(II) tartrate complexes in aqueous solutions, Russ. J. Coord. Chem. Khimiya. 31 (2005) 623-626. https://doi.org/10.1007/s11173-005-0146-7.

[43] H. Bessaies-Bey, J. Fusier, M. Hanafi, S. Zhang, M. Destarac, S. Jouenne, N. PassadeBoupat, F. Lequeux, J.B. d'Espinose de Lacaillerie, N. Sanson, Competitive adsorption of PAM and HPAM on siliceous material, Colloids Surfaces A Physicochem. Eng. Asp. 579 (2019) 1-6. https://doi.org/10.1016/j.colsurfa.2019.123673.

[44] H. Bessaies-Bey, R. Baumann, M. Schmitz, M. Radler, N. Roussel, Organic admixtures and cement particles: Competitive adsorption and its macroscopic rheological consequences, Cem. Concr. Res. 80 (2016) 1-9. https://doi.org/10.1016/j.cemconres.2015.10.010.

[45] A. Govin, M.C. Bartholin, W. Schmidt, P. Grosseau, Combination of superplasticizers 
with hydroxypropyl guar, effect on cement-paste properties, Constr. Build. Mater. 215 (2019) 595-604. https://doi.org/10.1016/j.conbuildmat.2019.04.137.

[46] J. Plank, C. Winter, Competitive adsorption between superplasticizer and retarder molecules on mineral binder surface, Cem. Concr. Res. 38 (2008) 599-605. https://doi.org/10.1016/j.cemconres.2007.12.003.

[47] H.M. Rietveld, A profile refinement method for nuclear and magnetic structures, J. Appl. Crystallogr. 2 (1969) 65-71. https://doi.org/10.1107/s0021889869006558.

[48] A.A. Coelho, TOPAS-Academic, Version 6: Technical Reference, 2016. http://www.bruker-axs.de/.

[49] V. Kahlenberg, I. Galuskina, B. Krüger, A. Pauluhn, E. Galuskin, Structural investigations on bredigite from the Hatrurim Complex, Mineral. Petrol. 113 (2019) 261-272. https://doi.org/10.1007/s00710-018-0646-z.

[50] G. Álvarez-Pinazo, A. Cuesta, M. García-Maté, I. Santacruz, E.R. Losilla, A.G.D. La Torre, L. León-Reina, M.A.G. Aranda, Rietveld quantitative phase analysis of Yeelimite-containing cements, Cem. Concr. Res. 42 (2012) 960-971. https://doi.org/10.1016/j.cemconres.2012.03.018.

[51] C. Gay, E. Raphaël, Comb-like polymers inside nanoscale pores, Adv. Colloid Interface Sci. 94 (2001) 229-236. https://doi.org/10.1016/S0001-8686(01)00062-8.

[52] E. Kohler, A. Ali, J. Harvey, Draft Report Goal 4 Long Life Pavement Rehabilitation Strategies - Rigid : Flexural Fatigue Life of Hydraulic Cement Concrete Beams, 2005.

[53] Standard NF EN 196-1 : Cement test methods - Part 1: determination of strengths, (2006). 
[54] R. Snellings, J. Chwast, Ö. Cizer, N. De Belie, Y. Dhandapani, P. Durdzinski, J. Elsen, J. Haufe, D. Hooton, C. Patapy, M. Santhanam, K. Scrivener, D. Snoeck, L. Steger, S. Tongbo, A. Vollpracht, F. Winnefeld, B. Lothenbach, Report of TC 238-SCM:

hydration stoppage methods for phase assemblage studies of blended cements - results of a round robin test, Mater. Struct. Constr. 51 (2018). https://doi.org/10.1617/s11527018-1237-5.

[55] Q. Zhou, F.P. Glasser, Thermal stability and decomposition mechanisms of ettringite at $<120^{\circ} \mathrm{C}$, Cem. Concr. Res. 31 (2001) 1333-1339. https://doi.org/10.1016/S00088846(01)00558-0.

[56] K. Scrivener, R. Snellings, B. Lothenbach, A practical guide to microstructural analysis of cementitious materials, Taylor \& Francis Group, 2016. https://doi.org/https://doi.org/10.1201/b19074.

[57] ICDD, PDF-4, in: ICDD, (Ed.), The International Center for Diffraction Data, (2008).

[58] L. Pelletier, F. Winnefeld, B. Lothenbach, The ternary system Portland cement-calcium sulphoaluminate clinker-anhydrite: Hydration mechanism and mortar properties, Cem. Concr. Compos. 32 (2010) 497-507. https://doi.org/10.1016/j.cemconcomp.2010.03.010.

[59] Y. Liao, X. Wei, G. Li, Early hydration of calcium sulfoaluminate cement through electrical resistivity measurement and microstructure investigations, Constr. Build. Mater. 25 (2011) 1572-1579. https://doi.org/10.1016/j.conbuildmat.2010.09.042.

[60] S. Gwon, S.Y. Jang, M. Shin, Combined effects of set retarders and polymer powder on the properties of calcium sulfoaluminate blended cement systems, Materials (Basel). 11 (2018). https://doi.org/10.3390/ma11050825. 
[61] A. Cuesta, G. Álvarez-Pinazo, S.G. Sanfélix, I. Peral, M.A.G. Aranda, A.G. De La Torre, Hydration mechanisms of two polymorphs of synthetic ye'elimite, Cem. Concr. Res. 63 (2014) 127-136. https://doi.org/10.1016/j.cemconres.2014.05.010.

[62] R.J. Flatt, J. Zimmermann, C. Hampel, C. Kurz, I. Schober, L. Frunz, C. Plassard, E. Lesniewska, The Role of Adsorption Energy in the Sulfate-Polycarboxylate Competition, in: 9th CANMET/ACI Int. Conf. Superplast. Other Chem. Admixtures Concr. A.C.I., 2009: pp. 153-164.

[63] F. Dalas, S. Pourchet, A. Nonat, D. Rinaldi, S. Sabio, M. Mosquet, Fluidizing efficiency of comb-like superplasticizers: The effect of the anionic function, the side chain length and the grafting degree, Cem. Concr. Res. 71 (2015) 115-123. https://doi.org/10.1016/j.cemconres.2015.02.001.

[64] T. Su, X. Kong, H. Tian, D. Wang, Effects of comb-like PCE and linear copolymers on workability and early hydration of a calcium sulfoaluminate belite cement, Cem. Concr. Res. 123 (2019) 105801. https://doi.org/10.1016/j.cemconres.2019.105801.

[65] R.J. Flatt, Y.F. Houst, A simplified view on chemical effects perturbing the action of superplasticizers, Cem. Concr. Res. 31 (2001) 1169-1176. https://doi.org/10.1016/S0008-8846(01)00534-8. 